\title{
IMPUNIDAD EN EL SALVADOR Y GUATEMALA: «DE LA LOCURA A LA ESPERANZA: ¿NUNCA MÁS?» «De la locura a la esperanza: ¿Nunca Más?». Impunity in El Salvador and Guatemala
}

\author{
Elena MARTÍNEZ BARAHONA \\ Universidad de Salamanca, España \\ \embarahona@usal.es \\ Martha Liliana GUTIÉRREZ SALAZAR \\ Universidad de Salamanca, España \\ \gutierrezsalazar@usal.es \\ Liliana RINCÓN FONSECA \\ Universidad de Salamanca, España \\ \ilianarinconf@gmail.com
}

BIBLID [1130-2887 (2012) 61, 101-136]

Fecha de recepción: 15 de abril del 2012

Fecha de aceptación: 19 de junio del 2012

RESUMEN: El tema de las transiciones a la democracia ha sido abordado principalmente desde las élites políticas. Los estudiosos han encontrado que en el primer momento de la transición es el pulso entre dichos grupos el que determinará qué tipo de medidas se adoptan, y si incluyen los juicios a los represores. Sin embargo, más allá de dichas decisiones, el Poder Judicial, la sociedad civil e incluso cambios de gobierno pueden influir el proceso, y las políticas de verdad y justicia adoptadas en un principio pueden cambiar mucho tiempo después. Este tema, que se viene estudiando en el Cono Sur de América Latina, ha sido menos explorado en Centroamérica, donde el énfasis inicial se puso en la verdad, y los esfuerzos por judicializar las violaciones del pasado apenas cuentan con algunos resultados iniciales en el ámbito nacional. Es por ello que este trabajo se propone explorar y explicar el desarrollo y estado actual de los mecanismos de justicia transicional en Guatemala y El Salvador, poniendo énfasis en la judicialización de los crímenes ocurridos durante los conflictos armados, su evolución y el papel que han jugado diversos actores nacionales en estos procesos.

Palabras clave: justicia postransicional, impunidad, Guatemala y El Salvador. 
ABSTRACT: The issue of transition to democracy has been approached mainly from political elite perspective. Researchers have found that fights amongst elite groups determine what measures are taken during the first steps of policial transitions -including trials to repressors. However, Judiciary branch, civil society and changes in Government can influence the process- bringing about changes in justice policies further later. This issue, which has been studied in Latin American Southern Cone, is less studied in Central America, where the emphasis was placed on search of truth, and on the efforts made to prosecute past human rights violations -with little initial results at a national level. That is why this work is aimed to explore the development and current status of the mechanisms of transitional justice in Guatemala and El Salvador, focused on the prosecution of crimes committed during the conflict, and its evolution and the played role by national and international actors.

Key words: post-transitional justice, impunity, Guatemala and El Salvador.

\section{INTROdUCCIÓN: JUSTICIA POSTRANSICIONAL E IMPUNIDAD EN CENTROAMÉRICA ${ }^{1}$}

Tradicionalmente se ha utilizado el término de «justicia transicional» para referirse a la justicia asociada con procesos de cambio político y con las respuestas legales para enfrentar los crímenes de los regímenes represores (Teitel 2003: 69). En un sentido análogo y de manera más amplia, Skaar (2011: 2) la entiende como aquella compuesta por los mecanismos formales o informales dirigidos a conjurar las violaciones del pasado, que incluyen juicios, comisiones de la verdad, amnistías, purgas, programas de reparación, entre otros, pero siempre referida a las medidas adoptadas en un primer momento después de la caída de los regímenes militares. O’Donnell y Schmitter (1986) fueron los primeros que afrontaron el dilema de cómo afrontar el pasado sin perjudicar la transición a la democracia. Huntington (1991: 208 y 228), sobre este mismo problema, indicaría que las medidas de justicia transicional dependerían según el poder político:

Los oficiales de regímenes autoritarios fuertes que voluntariamente los terminaron no fueron enjuiciados; oficiales de regímenes autoritarios que colapsaron fueron castigados, si fueron apropiadamente enjuiciados por el nuevo régimen democrático².

1. Este artículo se inserta dentro del Proyecto 10-CAP2-1874 «Lucha Contra la impunidad y justicia transicional en Centroamérica» financiado por la Agencia Española de Cooperación Internacional para el Desarrollo (AECID), en el marco de la Convocatoria Abierta y Permanente (CAP) para actividades de Cooperación y Desarrollo. Las autoras agradecen los comentarios en aquel foro, así como las importantes sugerencias de dos evaluadores anónimos de América Latina Hoy a una primera versión de este artículo. Respecto al título, «De la locura a la esperanza: la guerra de 12 años en El Salvador» y «Guatemala, Nunca más» son los títulos de los informes de las Comisiones de la verdad en El Salvador (1993) y Guatemala (1998), respectivamente.

2. Traducción propia. A continuación el texto original: «Officials of strong authoritarian regimes that voluntarily ended themselves were not prosecuted; officials of weak authoritarian regimes that collapsed were punished, if they were promptly prosecuted by the new democratic government». 
En la actualidad, algunos autores ya no se centran sólo en el período de democratización, sino que han comenzado a utilizar el término de «justicia postransicional» para hacer referencia a aquella justicia frente a violaciones de derechos humanos cometidas durante el régimen militar, que se lleva a cabo después de la transición de la democracia. La literatura, sin embargo, difiere tanto del modo y alcances de dicha «justicia» como del tiempo en el que se toma después de las transiciones. Así, mientras algunos autores se centran sólo en las acciones judiciales (ya sea a través de causas penales o juicios civiles), llevadas a cabo por lo menos un ciclo electoral después de la transición a la democracia (Skaar 2011: 29), otros incluyen más mecanismos de justicia transicional en un tiempo no definido después de las transiciones (Collins 2010).

Lo que tienen en común estas definiciones de justicia postransicional es la idea de marcar diferencias con la llamada escuela clásica de la justicia transicional (Collins, 2010: 2), que enfatizaba la importancia del pulso político entre las élites al momento de la quiebra de los regímenes, pulso que definiría finalmente la adopción o no de juicios, comisiones de la verdad y reparaciones ${ }^{3}$. En este pulso cobran especial importancia los dos modelos de comisiones de la verdad que podrían de alguna manera condicionar posibles juicios posteriores. El primero, que se define por la propuesta de sacrificar la justicia retributiva en aras de la verdad y la reconciliación (seguido por la Comisión Surafricana de Verdad y Reconciliación), tuvo como problema fundamental tener que justificar moralmente el intercambio de dicha justicia por la verdad (Gutmann y Thomson 2000; Kiss 2002; Du Toit 1999). El segundo, que fue desarrollado en Argentina (Comisión Nacional sobre la Desaparición de Personas, CONADEP en 1983), Chile (Comisión Nacional de Verdad y Reconciliación de 1990) y Perú (Comisión Nacional de Verdad y Reconciliación, CVR en 2002), concibe la búsqueda y develamiento de la verdad como una práctica que debe servir no sólo para obtener una narrativa de las pasadas violaciones de los derechos humanos, sino también para fortalecer los mecanismos judiciales de procesamiento, juicio y castigo (Malamud-Goti 2003) ${ }^{4}$.

Hay que indicar aquí que, al considerar que la justicia retributiva podía hacer fracasar los procesos de transición, los primeros defensores de las comisiones de la verdad en América Latina propusieron que aquella debía ser aplazada (Cortés Rodas 2007: 709) por lo que al inicio de las transiciones, la mayoría de países decidieron afrontar el pasado sin acudir a los juicios. Sin embargo, pasados unos años en varias Cortes latinoamericanas se iniciaban casos de derechos humanos contra militares y otros partícipes de los

3. Los estudios clásicos de justicia transicional señalan que «la variable clave es la fuerza relativa de los grupos prorreforma que surgen del antiguo régimen, los grupos moderados de oposición y los grupos intransigentes de ambos lados» (E. BARAHONA DE BRITO et al. 2002: 44), y por lo tanto en el primer momento de la transición es el pulso entre dichos grupos el que determinará qué tipo de medidas se adoptan, y si incluyen los juicios a los represores (G. O’DONNELL y P. SCHMiTTER 1986; T. KARL 1990). En la misma línea, uno de los grandes debates sobre justicia transicional se ocupa de la tensión entre paz y justicia: mientras algunos autores resaltan la necesidad de tener en cuenta las limitaciones de la justicia (J. ELSTER 1995; M. OSIEL 2005), otros abogan por la necesidad de que haya castigo (J. McAdams 1997; H. ValenCia Villa 2007).

4. Sobre esta diferencia entre modelos de comisiones de verdad ver N. Roth-ArRiAZA (2006: 3). 
períodos represivos, manteniéndose hasta la fecha las demandas de verdad, justicia y reparación, con trayectorias distintas en cada caso.

Estas trayectorias dependerían de varias variables explicativas. Así mientras Skaar (2010: 2) indica que el refuerzo de la independencia judicial a través de las reformas judiciales y constitucionales ha hecho que los jueces más favorables a los juicios no se vieran constreñidos por poderes ejecutivos contrarios a ellos ${ }^{5}$, Collins (2010: 6) resalta a los sujetos privados que reclaman accountability y al cambio de actitudes judiciales frente a la rendición de cuentas como los actores y escenarios claves en la justicia postransicional (Collins 2010: 6 y 59). Ambas autoras destacan el desplazamiento hacia el Judicial de la tradicional atención prestada al papel de los poderes Legislativo y Ejecutivo en relación a las políticas hacia el pasado confiriéndole ser el primer interlocutor institucional de los autores que reclaman justicia (Skaar 2011: 26 y Collins 2010: 36-37).

Otros estudios han intentado explicar por qué en algunos casos las Cortes Supremas son más activas respecto a la protección de los derechos humanos. En este sentido, Gutiérrez Salazar (2011) en su estudio sobre Guatemala y los casos judicializados del conflicto armado, llega a la conclusión de que es la composición de las Cortes la que incide directamente en dicha protección, así como el impulso que las víctimas y sus familiares dan a los procesos ${ }^{6}$.

Los trabajos de Collins (2010) y Skaar (2011) aunque novedosos, al centrarse en explicar las variaciones en cuanto a juicios a través del tiempo en diferentes países, se nutren, como el presente, de una gran variedad de estudios teóricos y empíricos? ${ }^{7}$. Sin embargo, tenemos que indicar aquí las dificultades que existen en la actualidad para teorizar sobre las medidas de justicia transicional. Así, la literatura actual todavía adolece de estudios que generalicen sobre los determinantes de dichas políticas frente al pasado. Hay interesantes estudios de caso, pero pocas comparaciones sistemáticas ${ }^{8}$.

5. E. SKAAR (2011:39) indica que se deben dar en todo caso tres precondiciones: una reducción de las amenazas de los militares, una persistente demanda de justicia y bases legales suficientes para los enjuiciamientos.

6. Se encontró que en los casos en que las sentencias son dictadas por magistrados con mayor tradición en el sector judicial y que no tienen familiares en política, es más probable la protección judicial de derechos humanos. Los reclamos de justicia por parte de víctimas o sus familiares, y la existencia de decisiones previas de Cortes internacionales, también inciden positivamente. Además de lo anterior, se encontró que cuando los encausados tienen un alto perfil y se mantienen activos en la vida política del país, la Corte de Constitucionalidad falla en contra de la protección de derechos humanos y no así la Corte Suprema.

7. Además de las citadas autoras, aquí prestamos especial atención a literatura de transiciones (G. O'Donnell y P. SCHMitTer 1986; T. KARL 1990), justicia transicional (J. MCAdAMS 1997; E. BARAHONA DE BRito et al. 2002; R. Teitel 2003; H. VAlenCia Villa 2007), influencia de factores internacionales en juicios nacionales y en cambio doméstico (T. RisSE y K. SikKINK 1999; N. Roth-ARRIAZA 2002; C. Booth WaLling y K. SiKkink 2008) o los determinantes sociales (P. Aguilar, L. BALCELLS y H. CEBOLLA 2011), entre otros.

8. Como excepción, podemos citar aquí los trabajos de M. NALEPA (2010a y 2010b) que analizan los casos de Polonia, Hungría y la República Checa para explicar por qué en algunos casos las medidas de justicia transicional son adoptadas o evitadas. 


\section{I.1. Una región por explorar}

Pese a la centralidad del tema de justicia transicional en Centroamérica, la ausencia de trabajos al respecto es llamativa. Entre los escasos estudios, podemos destacar el volumen en perspectiva comparada de Sieder (2002), que indaga por el papel de las políticas de la memoria en El Salvador, Honduras y Guatemala. Una comparación entre El Salvador y Chile es la realizada por Collins (2010) en su trabajo citado en líneas anteriores sobre justicia postransicional.

Sobre los casos concretos de El Salvador y Guatemala podemos citar, entre otros, el trabajo de Pásara y Wagner (2000) que, en el marco de la Misión de Verificación de las Naciones Unidas en Guatemala (MINUGUA), ofrece una bibliografía crítica sobre la temática de la justicia en Guatemala, que tuvo sus consecuencias después de los Acuerdos de Paz y los planteamientos de reforma que los acompañaron?. Pásara (2010) ahonda en el análisis de los cambios en el sistema de justicia después de los Acuerdos de Paz, en el estudio empírico de decisiones judiciales ${ }^{10}$, así como en el tema de la aplicación judicial de derechos humanos. El autor se pregunta por las razones que explican que los derechos humanos reciban una protección insuficiente en Centroamérica y Panamá, y para responder a la cuestión efectúa un análisis de la ubicación, en el orden interno, de las normas de origen internacional que dan respaldo a los derechos humanos, para luego presentar hallazgos sobre deficiencias formativas de los jueces centroamericanos y terminar resaltando otras dificultades, como la falta de independencia judicial y la insuficiente atención que se presta a las resoluciones judiciales ${ }^{11}$.

Respecto a El Salvador Popkin (2000) hace un completo estudio sobre la transición, la reforma al sistema judicial y la decisión adoptada por los actores políticos de dejar de lado cualquier posibilidad de accountability para los crímenes cometidos durante la guerra, llamando desde entonces la atención sobre la importancia de un Poder Judicial fuerte e independiente para que pueda hablarse de Estado de Derecho, respeto a los derechos humanos y consolidación de la democracia. En este mismo sentido, Collins (2010), al comparar Chile y El Salvador, advierte cómo el último ofrece el contraste de un país

9. Los autores incluyen, además, el texto sobre justicia contenido en el informe «Memoria del Silencio», elaborado por la Comisión de Esclarecimiento Histórico, así como algunos capítulos del informe «Una nueva justicia para la paz», de la Comisión de Fortalecimiento de la Justicia, emitido en virtud de compromisos contenidos en los acuerdos de paz.

10. El análisis de un universo de 494 sentencias, donde examina aspectos formales y de interpretación de los fallos, permite al autor trazar las características del juez promedio guatemalteco: «La actitud predominante entre muchos juzgadores, según sus decisiones, parece ser la de llevar a cabo una tarea con cuyos objetivos finales no se hayan genuinamente comprometido. De ahí ese "salir del paso" que se adivina en la tendencia ritualista que, carente de una conciencia acerca del papel trascendente del que es responsable socialmente, se ampara en la formalidad para no administrar justicia» (L. PÁsARA 2010: 156).

11. Al respecto señala: «La falta de publicidad de las resoluciones y de crítica profesional sobre ellas otorga cierto grado de impunidad a aquellas decisiones judiciales condescendientes con las violaciones de derechos humanos y, al mismo tiempo, desalienta y frustra los esfuerzos de algunos jueces, encaminados a poner en vigencia efectiva las normas existentes al respecto» (L. PÁSARA 2010: 226-227). 
cuyas instituciones jurídicas fueron ampliamente reformadas durante la transición, a pesar de lo cual se mantiene la amnistía y no hay un movimiento pro-accountability fuerte (Collins 2010: 4 y 211). Esto se debe, entre otras razones, al alto grado de discreción que tiene la Fiscalía, cuyos titulares se han opuesto a los esfuerzos contra la impunidad por los crímenes del pasado, a lo que se suma que los dos grandes partidos del país tienen interés en que se mantenga la amnistía, que todavía se defiende como el precio de la paz.

Así mismo, la autora señala cómo la intervención de actores internacionales en el proceso transicional tuvo el efecto no deseado de debilitar a los activistas de derechos humanos $^{12}$, que no desarrollaron hábitos legales para encaminar sus demandas y que la presión de las víctimas por justicia ha sido mucho menor que en el Cono Sur, donde además tienen un perfil distinto. Finalmente, Collins (2010: 211-212) destaca que aun cuando unos pocos casos de violaciones a los derechos humanos han sido llevados a la justicia en El Salvador, el bajo perfil de sus autores hace que no representen una quiebra para fijar precedentes de interpretación, como tampoco lo hacen las decisiones sobre la constitucionalidad de la ley de amnistía, que no implican avances significativos ni exigibles a los demás jueces.

Podemos indicar entonces que los escasos trabajos sobre justicia transicional en la región se presentan como interacción entre la misma y las reformas judiciales en América Latina. En este sentido, también Domingo (2011) analiza el impacto de doble vía que tienen ambos aspectos, donde la mayor eficacia de los mecanismos de rendición de cuentas que han implicado las reformas judiciales incide en reclamaciones de justicia respecto violaciones a los derechos humanos, mientras la evolución de estos juicios puede llevar a un reposicionamiento de los propios jueces. Sin embargo, tal y como analizaremos posteriormente, en Centroamérica muchas de las reformas judiciales que se implementaron después de los Acuerdos en los términos de las recomendaciones de las Comisiones de la Verdad no han tenido una incidencia real en mejorar o procurar una garantía efectiva del derecho a la justicia de las víctimas.

\section{I.2. Plan de trabajo}

Dentro del marco descrito, este trabajo se propone explorar y explicar el desarrollo y estado actual de los mecanismos de justicia transicional en Guatemala y El Salvador, poniendo énfasis en la judicialización de los crímenes ocurridos durante los conflictos armados y su evolución. El artículo se dividirá en tres partes. En la primera se realizará una breve descripción de los antecedentes históricos que llevaron a la firma de los

12. Esto ya había sido advertido por M. POPKIN (2000) que sugiere que el involucramiento directo y sin precedentes de la ONU en todas las etapas del proceso de paz puede haber debilitado a las organizaciones de derechos humanos y por R. SIEDER (2002: 262), que anota que después del informe de la Comisión de la Verdad se minimizó la notoriedad de dichas organizaciones, lo que en parte podía deberse a su relativa dependencia de la izquierda revolucionaria, y en parte a que se vieron relegadas por la Misión de Verificación de las Naciones Unidas en El Salvador (ONUSAL), durante el período inicial de la transición. 
Acuerdos de Paz en ambos países. En una segunda parte se analizará qué se ha hecho en materia de juicios por violaciones a los derechos humanos ocurridos durante los conflictos internos en estos países y qué otros mecanismos se han desplegado para hacer efectivos los derechos de verdad y reparación de las víctimas de dichas violaciones o sus familiares. La tercera parte del artículo intentará ofrecer una explicación tentativa de la ausencia tanto de justicia como de políticas de la memoria en ambos países. Este estudio pretende entonces responder a la pregunta de investigación de por qué los esfuerzos de justicia postransicional en ambos países han fracasado o han sido muy escasos.

Cabe advertir que si bien nos ocupamos principalmente de indagar por el aspecto judicial, no nos limitamos al mismo, pues buscamos qué otros mecanismos se han puesto en marcha con el paso del tiempo, tanto por el Ejecutivo como por las organizaciones de derechos humanos y las propias víctimas o la sociedad civil. Tampoco limitamos temporalmente la indagación por la prosecución judicial, indagando así desde los inicios de los procesos de paz, y no como lo hacen otros estudios (Skaar 2011) que se ocupan de los juicios iniciados un ciclo electoral después de la transición.

Tenemos que adelantar la gran dificultad que existe en lo que a materia de juicios e investigaciones judiciales se refiere. A la hora de llevar a cabo las bases de datos, nos hemos encontrado con problemas en cuanto al acceso a la información pública, descoordinación entre la sociedad civil y las organizaciones de derechos humanos que impulsan o llevan los juicios, resultando de trascendental importancia un primer esfuerzo -todavía incompleto y en proceso- por mapear el estado de las denuncias o investigaciones por estos casos, en la medida que ha sido posible ${ }^{13}$. Aquí se marca la primera gran importancia con los estudios sobre el Cono Sur y otros países, donde es relativamente fácil determinar el número de investigaciones judiciales y condenas criminales en casos planteados contra los militares (Skaar 2011: 29).

Para evaluar qué se ha hecho en El Salvador y Guatemala frente a estos temas, lo que se planteó, como parte del proyecto financiado por la AECID, fue una exploración en campo y con fuentes secundarias, por un lado, de las causas, investigaciones e indagaciones judiciales por crímenes de lesa humanidad y graves violaciones a los derechos humanos cometidos durante los conflictos ocurridos en los dos países, y, por el otro lado, de los implicados en dichas causas e investigaciones. Lo anterior con base en modelos de bases de datos que llevan la Universidad Diego Portales en Chile y el Centro de Estudios Legales y Sociales (CELS) de Argentina, que desarrollan proyectos de justicia transicional en el Cono Sur ${ }^{14}$. Además se previó la necesidad de buscar

13. Queremos dar las gracias a Lilian del Río (de la Fundación Myrna Mack) por el excelente trabajo de recopilación de las bases de datos de procesos judiciales y políticas de la memoria que se realizaron bajo el patrocinio del Proyecto 10-CAP2-1874 «Lucha Contra la impunidad y justicia transicional en Centroamérica» financiado por la Agencia Española de Cooperación Internacional para el Desarrollo (AECID), en el marco de la Convocatoria Abierta y Permanente (CAP) para actividades de Cooperación y Desarrollo.

14. Las bases de datos fueron adaptadas, simplificándolas, ya que se preveía que la consecución de información en Centroamérica ofrecería mayores dificultades, más aun teniendo un tiempo limitado para desarrollar el trabajo de campo. 
información sobre exhumaciones y reparaciones, tanto mediante políticas públicas como por vía judicial o iniciativas de las propias víctimas y ONG.

Finalmente, debe recordarse que en América Central la agenda transicional fue sobredeterminada por la necesidad de poner fin al conflicto armado y son los Acuerdos de $\mathrm{Paz}$, en lugar de las elecciones, los que representan el momento transicional definitivo. En estos países la transición consistió, fundamentalmente, en la renuncia a la fuerza militar por parte de actores que, no obstante, continuaron dominando el panorama político posterior (Collins 2010: 159).

\section{Más Allá de los Acuerdos de Paz en El Salvador y Guatemala}

El Salvador fue un Estado militarizado mucho antes de que se librara abiertamente una guerra contra la insurgencia. Aunque la intervención de los militares en política fue histórica, al cerrar la década de 1970 se dio inicio a ataques masivos contra la población civil en general, en su mayoría desapariciones y asesinatos selectivos, violaciones, masacres y desplazamientos, encaminados a minar los apoyos rurales de la guerrilla. Entre 1978 y 1983 murieron a manos de agentes del Estado 42.171 personas, del total de 50.000 asesinadas, por ambos bandos, durante toda la guerra civil, delitos que, como las demás violaciones a los derechos humanos, quedaron impunes con la anuencia de un Poder Judicial cómplice del régimen (Sieder 2002: 250).

La salida negociada al conflicto fue propiciada por la incapacidad del ejército de derrotar militarmente al Frente Farabundo Martí para la Liberación Nacional (FMLN), a pesar de la ayuda recibida de Estados Unidos. Desde la creación del partido Alianza Nacional Republicana (ARENA) se empezó a cuestionar al Estado Mayor, a lo que se sumó la incapacidad del ejército para mantener la seguridad de San Salvador, lo que fue puesto en evidencia por el FMLN con la ofensiva de noviembre de 1989. Después de casi tres años de negociaciones entre el gobierno y el FMLN, el 16 de enero de 1992 se firmaron los Acuerdos de Chapultepec, fijando las condiciones del ingreso del FMLN a la vida civil y política de El Salvador, que pasaban por la reducción del poder del ejército, la desmilitarización del sistema político y la reforma a la justicia ${ }^{15}$.

El proceso de paz en El Salvador, protagonizado por ARENA y el FMLN, ha sido caracterizado por la comunidad internacional como un proceso exitoso, ya que logró poner fin al conflicto. Sin embargo, como otros procesos de paz y como se verá más adelante, ha tenido algunas limitaciones como aquellas que tienen que ver con los derechos de verdad, justicia y reparación de las víctimas y sus sobrevivientes. En este sentido, el punto 5 del capítulo 1 del Acuerdo de Paz reconoce la necesidad de superar la impunidad reinante en las Fuerzas Armadas, sometiendo el asunto a la Comisión de la Verdad,

15. El Acuerdo de Paz de Chapultepec contiene nueve capítulos, así: 1) Fuerza Armada, 2) Policía Nacional Civil, 3) Sistema judicial, 4) Sistema electoral, 5) Cuestión Económica Social, 6) Participación política del FMLN, 7) Cese del enfrentamiento armado, 8) Verificación por las Naciones Unidas y 9) Calendario de ejecución. 
sin que ello obste para que los tribunales de justicia apliquen las sanciones que correspondan a quienes sean declarados responsables.

En Guatemala la doctrina de la seguridad nacional se instaló desde 1954 a 1985, con la consiguiente militarización de la política, legitimada mediante elecciones fraudulentas, y respaldada por la persecución y exterminio de comunidades indígenas, en un país con una población predominantemente indígena y mestiza, con una sociedad desestructurada y desintegrada (Alcántara 2008: 161). La creación de agentes rurales llamados «comisionados militares» y la exacerbación de la polarización y aumento de la violencia llegaron a su culmen en 1982, año en que surgió la Unidad Revolucionaria Guatemalteca (URNG) agrupando movimientos guerrilleros que defendían la lucha armada y año también en el que el ya violento gobierno de Fernando Romeo Lucas García cayó por el golpe de Estado perpetrado en su contra por José Efraín Ríos Montt, a quien le bastó un año para ejecutar su política de «tierra arrasada» ${ }^{16}$. La prolongación del conflicto durante 36 años y la violencia desplegada por el Estado, responsable de más del 90 por ciento de las violaciones a los derechos humanos, hacen que en Guatemala la cifra de violaciones a derechos humanos sea inmensamente mayor a la de los demás países de la región, de forma tal que los informes que se recabaron después de los Acuerdos dan cuenta de 500.000 muertos y desaparecidos (Skaar 2011: 4 y 5), cifra muy por encima de las que ya se comentaron para El Salvador, y muchísimo más que las reportadas en el Cono Sur.

Ríos Montt fue depuesto por el mando militar y durante el siguiente gobierno, encabezado por el general Óscar Mejía Vítores, se convocó la Asamblea Nacional Constituyente que dio origen a la Constitución de 1985, que estableció un marco jurídico propicio para la protección de derechos humanos y la independencia judicial, salvo porque limitó el período de jueces y magistrados de todos los rangos a cinco años.

En 1990 se puso en marcha la Comisión de Reconciliación Nacional y se reabrieron negociaciones con la Unidad Revolucionaria Nacional Guatemalteca (URNG) y en 1994 se suscribió el Acuerdo de Derechos Humanos que instauraría la Misión de Naciones Unidas para la verificación de los derechos humanos en Guatemala (MINUGUA), que adelantó trabajos de verificación una década. En diciembre de 1996, durante el gobierno de Álvaro Arzú, se firmó en Ciudad de Guatemala el Acuerdo de Paz Firme y Duradera, que ponía fin al conflicto armado entre la URNG y el Estado.

Contrario a lo sucedido en El Salvador, donde el enfrentamiento militar entre la guerrilla y el ejército había llegado a un punto muerto, en Guatemala la URNG estaba muy

16. Según las conclusiones y recomendaciones (II. n. ${ }^{\circ}$ 86) del Informe de la Comisión para el Esclarecimiento Histórico (CEH 1999) las denominadas operaciones de tierra arrasada, que comenzaron en febrero de 1982 (79), fueron «planificadas por las fuerzas del Estado» y «exterminaron por completo comunidades mayas, así como destruyeron sus viviendas, ganado, cosechas y otros elementos de sobreviviencia». La CEH registró 626 masacres atribuibles a estas fuerzas. Según el informe «esta política no sólo consistió en la eliminación física de los presuntos colaboradores de la insurgencia, sino también en la destrucción de todos los bienes y cultivos» (CEH 1999: 93), fue concebida para el aniquilamiento de la población a la que consideraban potencial base social del movimiento guerrillero (CEH 1999: 111) provocando así el exterminio casi total de comunidades indefensas (CEH 1999: 122). 
debilitada militarmente a la hora de firmar los acuerdos, y el ejército no sólo se consideraba vencedor de la guerra, sino que además mantuvo buena parte de su poder, gracias a la subordinación de la élite política y el apoyo del empresariado (Sieder 2002: 255-256).

Aunque desde 1985 se había instaurado un marco jurídico propicio para la democratización, el camino estuvo plagado de obstáculos. Es así como después de los acuerdos, y desde aparatos estatales, se cometieron crímenes que se consideran paradigmáticos, como el asesinato de la antropóloga Myrna Mack (septiembre 1990), que realizaba investigaciones sobre desplazamientos en virtud del conflicto, o el de monseñor Gerardi (abril 1998), ultimado casi inmediatamente después de entregar el informe de la verdad que encabezó desde el Arzobispado de Guatemala. Aun cuando se iniciaron investigaciones judiciales por estos crímenes, las mismas estuvieron plagadas de dificultades, dilaciones, viciadas por amenazas e incluso la muerte de quienes contribuían al esclarecimiento de los hechos, y todavía hoy algunos esfuerzos por hacer justicia se frenan desde las más altas esferas del Estado.

Cabe destacar aquí que ambos procesos de paz fueron impulsados por la comunidad internacional. Organizaciones internacionales, tanto de carácter gubernamental como no gubernamental, participaron de los dos procesos, y la ONU se involucró directamente en ambos. En Guatemala con la asesoría para la redacción de la Ley de Amnistía y con la Misión de las Naciones Unidas (MINIGUA) que se encargó de la verificación del cumplimiento de los Acuerdos de Paz, mientras en El Salvador su papel fue aún más central y protagónico durante todo el proceso. A pesar del impulso internacional para la consecución de la paz en la región, las reformas y su implementación se hicieron de forma aislada en cada país, lo que no obsta para que quienes reclaman justicia en toda la región compartan algunas estrategias, como el accionar ante la Corte Interamericana de Derechos Humanos y ante la justicia española, en base al principio de jurisdicción universal.

Podemos concluir señalando que a pesar de que tanto en El Salvador como en Guatemala los Acuerdos de Paz y el proceso que los antecedió llamaron la atención sobre el problema de la impunidad y la necesidad de promover reformas para poner fin a ella, y a pesar de que en ambos países se reconoció la necesidad de mejorar la situación de los derechos humanos, como se verá los resultados son todavía insuficientes y la injusticia se mantiene.

\section{III. (IN) Justicia POSTRANSicional}

Guatemala y El Salvador son los dos países de América Latina que registran un mayor número de violaciones a los derechos humanos durante los períodos represivos, seguidos, por una gran diferencia numérica, de Argentina, Chile y Uruguay, tal como se ve en la Tabla I. Al mismo tiempo, como se indicará en este epígrafe, son los dos países donde menos esfuerzos se han hecho para hacer efectivos los derechos de verdad, justicia y reparación de las víctimas. 
E. MARTÍNEZ BARAHONA, M. L. GUTIÉRREZ SALAZAR Y L. RINCÓN FONSECA IMPUNIDAD EN EL SALVADOR Y GUATEMALA:

«DE LA LOCURA A LA ESPERANZA: ¿NUNCA MÁS?»

TABLA I

VIOLACIONES A LOS DERECHOS HUMANOS EN PERÍODOS REPRESIVOS

\begin{tabular}{lll}
\hline PAís & N. ${ }^{\circ}$ DE VÍCTIMAS & PERÍODO \\
\hline Guatemala & 500.000 muertos o desaparecidos & 36 años de guerra civil \\
\hline El Salvador & 50.000 muertos & 12 años de guerra civil \\
\hline Argentina & Entre 10.000 y 30.000 víctimas & $\begin{array}{l}\text { Régimen de las juntas militares } \\
\text { entre 1976 y 1983 }\end{array}$ \\
\hline Chile & Cerca de 3.500 muertos y desaparecidos & Régimen de Augusto Pinochet \\
\hline Uruguay & 164 desaparecidos & Dictadura militar de los años 70 \\
\hline
\end{tabular}

Fuente: Elaboración propia a partir de datos recogidos por E. SKAAR (2011: 4-5) y R. SIEDER (2002: 251).

En los siguientes epígrafes, realizaremos una descripción de lo realizado en los rubros de verdad, justicia y reparación, no sin advertir que estos son aspectos que en la práctica se entrecruzan, ya que los procesos judiciales en ocasiones implican acceso a la verdad y la reparación, y los informes de comisiones de la verdad pueden ser vistos como una forma de justicia, al igual que los programas de reparación. Sin embargo, hacer la separación no sólo permite dar orden a la investigación, sino distinguir dónde se ha puesto el énfasis, desde la transición hasta ahora.

\section{III.1. Verdad}

Tanto en El Salvador como en Guatemala en las negociaciones de paz se acordó el establecimiento de Comisiones de la Verdad para investigar las violaciones a los derechos humanos cometidas durante la guerra. En El Salvador la Comisión, integrada por extranjeros, y que se vio revestida de capacidad de hacer recomendaciones vinculantes, tuvo un gran impacto en sus revelaciones y recomendaciones. El informe, titulado De la locura a la esperanza: la guerra de 12 años en El Salvador y publicado en marzo de 1993, además de señalar que las Fuerzas Armadas y los paramilitares fueron responsables del 85 por ciento de las violaciones cometidas contra los derechos humanos, fue importante porque «ayudó a garantizar la destitución del Alto Mando en marzo de 1993» (Sieder 2002: 275) y porque, a pesar de presiones recibidas en contra, individualizó más de 40 militares responsables de estos crímenes, previendo la inactividad del Poder Judicial sobre estos temas (Sieder 2002).

Sin embargo, dicho informe no se vio reflejado en las reformas institucionales posteriores, que dependieron más de los equilibrios de poder entre el ejército, ARENA y el FMLN. Además, a pesar de que la Comisión recibió más de 20.000 denuncias de toda clase de violaciones, en su mayoría desapariciones, ejecuciones y torturas, el informe se centró en 33 casos emblemáticos, quedando «pendiente el conocimiento de lo ocurrido en muchos otros» (Lazo Fuentes y Rey Tristán 2011: 211; Sieder 2002). Por otro lado, los integrantes del Alto Mando que habían sido destituidos recibieron honores militares (Sieder 2002: 261) y aun cuando se creó una Comisión Ad-Hoc integrada por 
tres juristas, encargada de la depuración de las fuerzas militares, a los oficiales de alto rango se les permitió cumplir el tiempo que les faltaba para obtener su pensión.

En Guatemala, a pesar de que en un primer momento el ejército se mostró contario a cualquier forma de rendición de cuentas por las atrocidades cometidas, la Iglesia católica, organizaciones locales de defensa de los derechos humanos y la ONU insistieron en la conformación de Comisiones de la Verdad (Sieder 2002: 256) y la participación social fue más allá, hasta el punto de que se ha señalado como «el rasgo más característico del proceso de esclarecimiento de la verdad guatemalteco» (Sieder 2002: 265).

Hubo Comisión de la Verdad oficial entre 1996-1999 e informe no oficial en 1998. La primera fue la Comisión de Esclarecimiento Histórico (CEH) establecida en el marco de los Acuerdos de Paz y que dio como resultado el informe Guatemala, memoria del silencio, publicado en febrero de 1999, con participación de la Misión de Naciones Unidas para Guatemala (MINUGUA). La segunda fue producto del proyecto de Recuperación de la Memoria Histórica (REMHI), que promovió la Iglesia católica y había publicado en 1998 el informe Guatemala, Nunca Más.

Según datos contenidos en los informes de la CEH y el Proyecto de REMHI, durante los 36 años de conflicto en Guatemala se cometieron entre 160.000 y 200.000 ejecuciones extrajudiciales, y entre 40.000 y 50.000 desapariciones forzadas. La CEH documentó además 626 masacres, lo que sirvió para concluir que se habían cometido actos de genocidio contra el pueblo maya. El 93 por ciento de las violaciones a los derechos humanos fue atribuido a agentes del Estado.

El arzobispo monseñor Gerardi fue asesinado el 26 de abril de 1998, dos días después de la entrega de Guatemala Nunca Más y su cargo como obispo auxiliar de Guatemala y director de la Oficina de Derechos Humanos del Arzobispado (ODHAG) fue ocupado por Mario Enrique Ríos Montt, hermano del exdictador. El informe de la CEH fue tachado de falso por el Ejército y de sesgado por la derecha, mientras el presidente Álvaro Arzú rechazó muchas de sus recomendaciones, aduciendo que las cumplían otras instancias como resultado de los Acuerdos de Paz ${ }^{17}$. Nueve meses después, el 26 de diciembre de 1999 fue elegido presidente Alfonso Portillo, candidato del FRG, partido fundado y liderado por el general José Efraín Ríos Montt, quien obtuvo el cargo de presidente del Congreso.

\section{III.2. Justicia}

\section{III.2.1. (In) Justicia en El Salvador}

Entre las recomendaciones de la Comisión de la Verdad en El Salvador se encontraba la reforma del sistema judicial, con petición de dimisión del pleno de la Corte Suprema incluida, «por considerar que había facilitado activamente la impunidad de los

17. «[A]ntes de la publicación del informe, el presidente Arzú y el ministro de defensa, General Barrios Celda, habían reconocido públicamente la participación del Estado en los "excesos" del pasado» (R. SIEDER 2002: 269). 
militares y de los escuadrones de la muerte» (Sieder 2002: 260). Sin embargo, pasados cinco días de la aprobación del informe, el Congreso aprobó una amnistía general mediante el Decreto Legislativo n. ${ }^{\circ} 486$, que preveía la extinción tanto de la responsabilidad penal como de la civil ${ }^{18}$, convirtiéndola en la ley de este tipo más amplia en la región (Collins 2010: 165) y garantizando la impunidad incluso de las violaciones a garantías procesales cometidas desde el Poder Judicial, así como la imposibilidad de reclamar reparaciones por la vía judicial ${ }^{19}$.

Las recomendaciones de reforma al sistema judicial se relacionaban con la necesidad de superar un proceso penal vigente desde 1974, el cual era de carácter inquisitivo y se basada en dos etapas fundamentales: instrucción y plenario. Este procedimiento vulneraba varios principios, entre los que se pueden mencionar: el de celeridad y publicidad, debido a que las actuaciones eran de carácter reservado y en la mayoría escritas, disminuyendo así la posibilidad de mecanismos de control sobre la información recolectada en la investigación; el de imparcialidad, que delegaba en el juez la facultad de dirigir la investigación y de adelantar el juicio. Aunado a esto, se facultaba ${ }^{20}$ como órganos auxiliares de la justicia para la investigación de los hechos delictivos a los cuerpos policiales de la época, entre los cuales se encontraban: guardia nacional, la policía de hacienda, la policía nacional; cuerpos que, de acuerdo con informe de la Comisión de la Verdad, tienen un alto grado de responsabilidad en la comisión de violaciones a derechos humanos cometidas en la guerra civil.

Como resultado de los Acuerdos de Paz, el proceso de reforma al sistema judicial fue implementado a través de una reforma constitucional y del procedimiento penal ${ }^{21}$. Se reconoció la competencia constitucional de la Fiscalía General de la República (FGR), para dirigir la investigación del delito ${ }^{22}$, se incorporaron principios que acercaron en mayor medida el procedimiento penal, al sistema acusatorio, incorporando en varias de las etapas principios como el de oralidad y publicidad. También se delegó a la FGR la facultad de la promoción de la acción penal enmarcada en los principios de oportunidad y acusatorio, dejando a los jueces de manera exclusiva la competencia para adelantar el juzgamiento.

18. Al respecto C. CoLLINS advierte que: «No Latin American transitional settlement (except the Salvadorean) explicitly attempted to rule out private civil action over accountability» (C. CoLLINS 2010: 47).

19. En 1994 la Comisión Interamericana de Derechos Humanos (CIDH), en su informe sobre la situación de los derechos humanos en El Salvador, señaló: «En consecuencia, la Comisión... estima, con base en las consideraciones precedentes -independientemente de la eventual necesidad derivada de las negociaciones de paz, y de las razones eminentemente políticas-, que las amplísimas dimensiones de la ley general de amnistía aprobada por la Asamblea Legislativa de El Salvador constituyen una violación de las obligaciones internacionales asumidas por ese país al ratificar la Convención Americana sobre Derechos Humanos, al permitir, de una parte, la figura de la "amnistía recíproca", que no tuvo como paso previo un reconocimiento de responsabilidad (pese a las recomendaciones de la Comisión de la Verdad); su aplicación a crímenes de lesa humanidad; y la eliminación de la posibilidad de obtener una adecuada reparación patrimonial para las víctimas, principalmente». Esta posición ha sido mantenida por la Comisión en los casos individuales de los que ha conocido.

20. Decreto 450 de 1973. Código de Procedimiento Penal, artículo 11.

21. Decreto n. ${ }^{\circ} 904$ de 1996 y Decreto 733 de 16 de enero de 2009.

22. Constitución de la República de El Salvador, artículo 193, numeral 3. 
A pesar de estas reformas, el sistema de administración de justicia en materia penal no ha logrado superar tradiciones autoritarias que persisten desde la guerra civil. Así, aunque la FGR es un organismo independiente, la Policía Nacional Civil (PNC) -principal cuerpo auxiliar de la Fiscalía- depende directamente del Poder Ejecutivo, lo cual puede constituir un factor que atente contra el principio de independencia judicial. En la actualidad no se cuenta con la infraestructura necesaria ni técnica, ni humana, ni material, necesaria para realizar una investigación penal científica, siendo la prueba testimonial la prueba por excelencia en las investigaciones penales. Por último, tal y como demuestra el análisis del estado procesal de los casos bajo análisis, la ausencia de voluntad política por parte la FGR, para adelantar de manera eficiente las investigaciones, constituye en la actualidad un factor relevante generador de impunidad.

La ley de amnistía ha sido impugnada por la vía judicial varias veces. El 20 de mayo de 1993 la Corte Suprema de Justicia se pronunció al respecto, «la norma de la impunidad de facto, anterior a la transición, fue sustituida por una versión institucionalizada de la misma» (Collins 2010: 166). En 1997 y 1998 hubo nuevos intentos de impugnación, en respuesta a los cuales la Sala de Constitucionalidad de la CSJ se pronunció en septiembre de 2000, confirmando la constitucionalidad de la ley, «aun cuando en teoría abrió un espacio para que los jueces decidan sobre concesión o no de la amnistía, el fallo es menos generoso de lo que parece» (Collins 2010: 173), como quiera que la discrecionalidad de los jueces sólo existe para determinados delitos y en un determinado período de tiempo -aquellos cometidos dentro del período presidencial en el que fue expedida, que se inició el 1 de junio de 1989-, mientras la mayoría de asesinatos en este país tuvieron lugar mucho antes, entre 1978 y 1983 , cuando murieron más de 42.000 personas a manos de las fuerzas gubernamentales (Sieder 2002: 251). Se mantienen además otros obstáculos, así después de la sentencia del 2000 se trató de que fueran juzgados los autores intelectuales del asesinato de los jesuitas, sin embargo el caso fue cerrado aduciendo prescripción ${ }^{23}$.

Para realizar el mapeo general de los casos presentados ante la justicia penal nacional, se obtuvo información de siete entidades a través de entrevistas con sus representantes, una de carácter gubernamental -la Procuraduría para la Defensa de los Derechos Humanos- y seis de carácter no gubernamental: Tutela Legal del Arzobispado de San Salvador, la Fundación de Estudios para la Aplicación del Derecho (FESPAD), el Centro para la Promoción de los Derechos Humanos «Madeleine Lagadec», la Asociación Pro-Búsqueda de niños y niñas desaparecidos, la Comisión de Derechos Humanos de El Salvador (CDHES) y el Instituto de Derechos Humanos de la Universidad José Simeón Cañas (IDHUCA) ${ }^{24}$.

23. A la falta de justicia en el ámbito doméstico se suman dificultades para materializarla en otros tribunales. Así, en mayo de 2012 se conoció por informaciones de prensa que la Corte Suprema de Justicia de El Salvador negó la extradición de un grupo de 13 antiguos oficiales del Ejército salvadoreño, implicados en el asesinato, que son juzgados por la Audiencia Nacional en España, donde el crimen ha sido considerado de lesa humanidad. En: http://internacional.elpais.com/internacional/2012/05/09/actualidad/1336536325_011817 (acceso, 12 de mayo de 2012).

24. También se consultó la Corte Suprema de Justicia, Sala Penal y la Fiscalía General de la República. La Sala de lo Penal de la CSJ señaló que los casos sobre los cuales se le solicitó información no 
Además de lo anterior, se revisaron expedientes judiciales donde se determinó información relevante para 56 casos, de los cuales 33 están bajo conocimiento de la Fiscalía, entidad que, como ya se señaló, no suministró información. Dadas las restricciones de acceso a los expedientes propias de las investigaciones criminales y a la falta de colaboración de algunos despachos, se acudió de nuevo a las ONG que acompañan los diferentes casos, obteniendo información de las organizaciones que acabamos de referir, así como del Comité de Expresos Políticos (EXCOPPES). También se recibió información de la Procuraduría para la Defensa de los Derechos Humanos y se tuvo acceso a expedientes en los juzgados de paz de San Esteban, Tecoluca (San Vicente), en el Juzgado Primero de Instrucción de San Vicente (San Vicente), en el Juzgado de Paz de Suchitoto (Suchitoto), en el Juzgado de Paz de Usulután (Usulután), en el Juzgado de Primera Instancia de San Francisco Gotera (Morazán).

De los resultados obtenidos es posible señalar que durante el período de violaciones de derechos humanos entre 1975 a 1991, se cuenta con casos ocurridos en 12 de los 14 departamentos del país ${ }^{25}$. Se registra la apertura de investigaciones penales entre los años 1980 y 2011, de los cuales 18 denuncias fueron interpuestas durante el período de la guerra civil y 38 fueron presentadas en el período posterior a la firma de los Acuerdos de Paz (Tabla II).

\section{TABLA II}

RANGO DE FECHAS EN LAS CUALES SE INICIARON LAS INVESTIGACIONES DE LOS CASOS EN EL SALVADOR

\begin{tabular}{c|c|c|c}
\hline AÑO & CASOS & AÑO & CASOS \\
\hline 1980 & 3 & 1997 & 1 \\
1982 & 1 & 2000 & 2 \\
1983 & 1 & 2002 & 1 \\
1986 & 1 & 2003 & 2 \\
1988 & 6 & 2006 & 3 \\
1990 & 5 & 2008 & 7 \\
1991 & 1 & 2009 & 6 \\
1992 & 2 & 2010 & 8 \\
1993 & 1 & 2011 & 2 \\
1996 & 2 & Sin dato & 1 \\
\hline
\end{tabular}

Fuente: Elaboración propia, con base en la revisión de expedientes.

eran de su competencia, salvo aquellos donde se hubiese interpuesto recurso de casación, lo que no ha ocurrido en El Salvador. Por su parte, la Fiscalía General de la República no atendió las solicitudes de información escritas que se le hicieron.

25. Dichas violaciones se centraron principalmente en el departamento de San Salvador (17), en el departamento de San Vicente (7), en el departamento de Morazán (6) y en el departamento de Chalatenango (4). El resto ocurrieron en el departamento de La Paz (3), en el departamento de La Libertad (3), en el departamento de Cuscatlán (2), en el departamento de Cabañas (1), en el departamento de San Miguel (1), en el departamento de Sonsonate (1) y en el departamento de Usultán (1). En los 10 casos restantes no se logró establecer el departamento en el cual se cometieron los hechos. 
En relación con el avance en las investigaciones de los casos consignados en la base de datos es posible señalar que hasta la fecha se registran (ver Tabla III): 45 casos en etapa de diligencias previas de investigación, uno en instrucción, uno por el cual se condenó pero de manera posterior se aplicó la ley de amnistía, uno se declaró el sobreseimiento definitivo por prescripción debido a que no se consideró que el hecho correspondiera a un delito de lesa humanidad, en cuatro casos se declaró el sobreseimiento definitivo argumentando la ley de amnistía, un caso en preadmisión, un caso fue rechazado y en dos casos no fue posible encontrar la información. De los 56 casos registrados, 44 corresponden a investigaciones principales y 10 a investigaciones conexas.

TABLA III

EsTADO DE LOS PROCESOS EN El SALVADOR

\begin{tabular}{l|c}
\hline ETAPA PROCESAL & NÚMERO DE PROCESOS \\
\hline Diligencias iniciales de investigación & 45 \\
Instrucción & 1 \\
Condena pero se aplica ley de amnistía & 1 \\
Sobreseimiento por prescripción & 1 \\
Sobreseimiento ley amnistía & 4 \\
Preadmisión & 1 \\
Rechazada & 1 \\
Sin dato & 2 \\
\hline
\end{tabular}

Fuente: Elaboración propia, con base en la revisión de expedientes.

La gran mayoría de los casos analizados no han logrado superar etapas procesales cuyo objetivo es la recopilación de acervo probatorio para decidir si procede la etapa de juicio o no. Cabe destacar que en muchos de estos casos es notable el transcurso del tiempo durante esta etapa. Así mismo, es posible señalar que dentro de los expedientes que fue posible revisar, es notorio el bajo esfuerzo por parte de los funcionarios para recopilar y practicar pruebas conducentes a lograr una investigación eficaz.

Respecto al tipo de violaciones registradas en la base de datos es posible señalar que: 24 casos corresponden a desaparición forzada, 11 a ejecuciones extrajudiciales, 8 casos de masacres, 3 casos de tortura, 1 caso de violencia sexual y 1 de desaparición forzada con una posterior ejecución extrajudicial (Tabla IV). De los 56 casos registrados, sólo se cuenta con información judicial de los autores en dos casos. Sólo uno de los casos bajo estudio corresponde a un hecho cometido por la guerrilla del FMLN. Por otro lado, en ninguno de los casos analizados se ha activado dentro del ámbito interno la vía civil en busca del reconocimiento de la responsabilidad. 
E. MARTÍNEZ BARAHONA, M. L. GUTIÉRREZ SALAZAR Y L. RINCÓN FONSECA IMPUNIDAD EN EL SALVADOR Y GUATEMALA:

«DE LA LOCURA A LA ESPERANZA: ¿NUNCA MÁS?»

TABLA IV

RELACIÓN ENTRE EL TIPO DE VIOLACIÓN INVESTIGADO

Y EL ESTADO DE LA INVESTIGACIÓN EN EL SALVADOR

\begin{tabular}{cccc}
\hline \multirow{2}{*}{$\begin{array}{c}\text { NúmERO DE INVESTIGACIONES ADELANTADAS } \\
\text { POR TIPO DE VIOLACIÓN }\end{array}$} & \multicolumn{3}{c}{ ESTADO DE LA ACTIVIDAD JUDICIAL } \\
\cline { 2 - 4 } & $\begin{array}{c}\text { ACTIVO (NO TERMINADA, } \\
\text { EN MOVIMIENTO) }\end{array}$ & $\begin{array}{c}\text { ARCHIVADA } \\
\text { (TERMINADA) }\end{array}$ & $\begin{array}{c}\text { SIN } \\
\text { INFORMACIÓN }\end{array}$ \\
\hline 24 casos de desaparición forzada & 22 casos & 2 casos & $\mathrm{X}$ \\
\hline 11 casos ejecución extrajudicial & 3 casos & 7 casos & 1 caso \\
\hline 8 casos de masacres & 2 casos & 5 casos & 1 caso \\
\hline 1 caso de desaparición y ejecución extrajudicial & $\mathrm{X}$ & 1 caso & $\mathrm{X}$ \\
\hline 3 casos de tortura & 3 casos & $\mathrm{X}$ & $\mathrm{X}$ \\
\hline 1 caso de violencia sexual & $\mathrm{X}$ & 1 caso & $\mathrm{X}$ \\
\hline 1 caso sin dato & $\mathrm{X}$ & $\mathrm{X}$ & 1 caso \\
\hline
\end{tabular}

Fuente: Elaboración propia, con base en la revisión de expedientes.

Al respecto, es posible señalar que el mayor número de casos relacionados con la desaparición forzada responde a la consolidación de una estrategia de litigio por parte de Pro-Búsqueda, organización dedicada exclusivamente a la búsqueda de niños y niñas desaparecidos (Tabla V). Podemos adelantar aquí una de las diferencias con Guatemala: la mayor debilidad inicial de las organizaciones de derechos humanos a la hora de acompañar los procesos judiciales. En este sentido FESPAD reconoce la falta de capacidad jurídica, el conocimiento más preciso de las herramientas para pedir justicia nacional e internacional así como la falta de energía:

[...] hay muchas deficiencias en las organizaciones sociales respecto a la formación en derecho internacional con el agravante de que en este momento internacional ya no es tan fuerte como era hace unos años, entonces las capacidades institucionales se han visto seriamente debilitadas no solo por cuestiones financieras, sino que con la llegada de este gobierno muchas personas que se habían formado por años se fueron, entonces, estamos volviendo a empezar a capacitar, estamos muy débiles, probablemente más débiles que después de la guerra.

También se reconocen los celos profesionales y la dispersión: «La cooperación internacional nos tiene sometidos a tal presión de presentar proyectos, de hacer medición de medios términos, de presentar informes finales, de auditorias, que estamos más preocupados por cumplir el proyecto, que por realmente tener incidencia en lo que pasa en la vida del país» ${ }^{26}$.

El Comité de Expresos Políticos también confirma la dispersión como uno de los principales obtáculos. Señalan también al trauma como otra de las dificultades de iniciar una investigación: «El solo hecho de plantearles que tienen que dar el testimonio

26. Entrevistas a informantes claves en FESPAD realizadas en San Salvador el 10 de febrero de 2012. 
o grabarlo, ya es una acción que les causa crisis, incluso hay personas que no quieren hablar sobre ese tema». Un tercer obstáculo que señalan es la falta de medios: «Todo el trabajo es voluntario y así también cuesta dar un tratamiento con los compañeros para que ellos puedan dar otros pasos en el ámbito judicial» ${ }^{27}$.

TABLA V

RELACIÓN DE CASOS POR ORGANIZACIÓN QUE ACOMPAÑA EL PROCESO EN EL SALVADOR

\begin{tabular}{l|c}
\hline \multicolumn{1}{c|}{ ORGANIZACIÓN QUE ACOMPAÑA EL PROCESO } & NÚMERO DE CASOS \\
\hline Tutela Legal & 3 casos \\
Tutela Legal/Comité para la promoción de los derechos humanos & \\
$\quad$ Madeleine Lagadec & 1 caso \\
Pro-Búsqueda/Cejil & 3 casos \\
Pro-Búsqueda & 18 casos \\
FESPAD & 1 caso \\
IDHUCA & 16 casos \\
Comité para la Promoción de los derechos humanos Madeleine Lagadec & 2 casos \\
Codefan/IDHUCA & 1 caso \\
Casos sin acompañamiento de organizaciones & 11 casos \\
\hline
\end{tabular}

Fuente: Elaboración propia, con base en la revisión de expedientes.

Por otra parte, de acuerdo a los registros de la investigación desde el 2001, algunos juzgados de paz han apoyado la solicitud de familiares de víctimas de masacres para adelantar procesos de exhumaciones. Aunque esto representa un avance respecto a garantizar a los familiares de las víctimas la posibilidad de realizar procesos de duelo, dichas exhumaciones no cumplen con los protocolos necesarios para la preconstitución de la prueba, ni dan inicio a ningún tipo de proceso penal pese a que la Fiscalía es informada de dichas diligencias, debido a que sólo se entiende como un trámite administrativo por motivos humanitarios.

Frente a los procesos de exhumación, en la exploración de campo y revisión de expedientes se encontraron diez casos en los cuales se han realizado exhumaciones. De los diez procesos, cinco han sido casos que han contado con el acompañamiento de las organizaciones de derechos humanos. Sin embargo, hasta la fecha ni las organizaciones ni las instituciones gubernamentales cuentan con un registro sistemático de las mismas, por lo cual la obtención de datos al respecto presentó dificultades.

Además de lo anterior, se logró tener conocimiento, a través del registro del libro diario, de la realización de 13 exhumaciones por motivos humanitarios realizadas por el Juzgado de Paz de Suchitoto (Cuscatlan), entre los años 2001 y 2011. De acuerdo a la información del juzgado, varios de estos casos cuentan con el acompañamiento del Centro para la Promoción de los Derechos Humanos «Madeleine Lagadec».

27. Entrevistas a informantes claves en Comité de Expresos Políticos realizadas en San Salvador el 2 de febrero de 2012. 
Podemos indicar que, en el caso salvadoreño, la impunidad ha sido mayor que la justicia en el país. Pese a las recomendaciones de los Acuerdos de Paz, la forma en que está diseñado el sistema de justicia (forma de nombramiento de magistrados, control de los jueces de primera instancia y de sus decisiones por parte de los superiores) permite que se mantenga el statu quo frente a la no garantía de los derechos de las víctimas. En este sentido, las pocas garantías de transparencia que el mismo modelo constitucional de nombramiento de los magistrados establece, así como una reiterada tradición de vinculación política partidista de los magistrados, permite altos niveles de injerencia política en el nombramiento y toma de decisiones de los magistrados. Así, podemos analizar el contexto de la toma de decisiones y el fallo como tal de la CSJ respecto a los casos de solicitud de extradiciones para el caso jesuitas.

Cabe destacar, sin embargo, el reciente impulso que dio el fallo emitido por la Sala de lo Constitucional (SC) ${ }^{28}$ de la Corte Suprema de Justicia (CSJ) en el año 2010 al derecho de las víctimas al acceso a la justicia. En esta decisión, el Tribunal abordó, entre otros temas, el estudio de la constitucionalidad del monopolio de la acción penal por parte de la FGR ${ }^{29}$. La sentencia determinó que la acción penal pública no es de competencia exclusiva de la FGR, como hasta la fecha de la sentencia se había interpretado. Señaló que de entenderlo así se estaría vulnerando el derecho a las víctimas a la administración de justicia y exhortó a la Asamblea Legislativa (AL) a que reformara el ordenamiento en materia penal procesal, con el fin de garantizar el derecho de las víctimas a la posibilidad de ejercer la acción penal, en caso de que la Fiscalía, por omisión, negligencia y desinterés o por renuncia expresa en virtud del ejercicio del principio de oportunidad, no realizara el requerimiento fiscal ante las instancias judiciales correspondientes.

Como consecuencia de este fallo, la AL expidió el Decreto 1010 de $2012^{30}$, que realizó reformas a la legislación en materia procesal penal en particular al artículo 17 del Código de Procedimiento Penal, permitiendo a las víctimas la conversión de la acción pública en acción privada, en caso de que el fiscal de la FGR no presente el requerimiento fiscal o no proceda al archivo de la investigación. Esto constituye un avance respecto a la garantía del derecho a la administración de justicia de las víctimas, quienes enfrentan tal y como se demuestra en la investigación una conducta de reiterada omisión por parte de la FGR, frente al deber constitucional de adelantar de manera pronta las investigaciones por los hechos que son objeto de denuncia por parte de los ciudadanos. No obstante este avance, los términos que el decreto estableció como plazo para que la FGR decida si admite la conversión de la acción pública en privada son amplios, lo cual puede comprometer la efectividad de la medida.

Respecto a esta circunstancia, informantes claves del FESPAD indican que,

[...] no hay interés de investigar. Hay como una decisión silenciosa de perdón y olvido [...]. Puedo afirmar sin temor a equivocarme, que aquí se ha tomado la decisión de

28. Sentencia de inconstitucionalidad 5-2001/10, del 23 de diciembre de 2010, sala de lo Constitucional, Corte Suprema de Justicia de El Salvador.

29. Decreto 733 de 2008, artículo 17 Código de Procedimiento Penal.

30. Decreto 1010 del 29 de febrero de 2012. Asamblea Legislativa. 
garantizar que el Fiscal General que se nombre sea una persona que garantice que los casos en impunidad van a seguir en la impunidad [...] Nosotros tenemos el valladar constitucional de que el inicio de una acción penal está restringida al Fiscal General de la República, hubo una resolución de la Sala de lo Constitucional en el 2010, que abre la posibilidad de que esto se amplíe pero esto necesita reformas legales, que todavía no se han hecho.

\section{Siguiendo esta misma línea se indica que}

[...] en el sistema judicial hay gravísimas carencias en materia de derechos fundamentales, eso trae como consecuencia que ellos no tienen la mínima idea de qué es un delito de lesa humanidad, de qué delitos son imprescriptibles. Un ejemplo de esto es el caso de los Jesuitas al cual no le aplica la amnistía, ese se intentó judicializar, la Fiscalía le da trámite lo plantea mal y el juez dice «No porque el caso ya prescribió». Usted se da cuenta que hay en los jueces una tremenda comodidad a aplicar el código penal y procesal penal sin tener en cuenta un marco constitucional, un marco de derecho internacional que podría habilitar que algunos casos se judicializaran ${ }^{31}$.

\section{III.2.2. (In) Justicia en Guatemala}

En 1994 se reformó la justicia penal, implantando el sistema acusatorio y en 1996, como parte de los Acuerdos de Paz, se planteó la reforma del sistema judicial, con el propósito de eliminar la impunidad y dotar de un papel más activo a los tribunales (Sieder 2002), pero incluso antes se habían hecho intentos de encausar a los culpables de las violaciones a los derechos humanos, principalmente por parte de la sociedad civil (Sieder 2002: 259).

En diciembre de 1996, después de un acuerdo entre el gobierno y la URNG, se emitió el Decreto n. ${ }^{\circ} 145$ de 1996, del Congreso de la República, conocido como Ley de Reconciliación Nacional, que no estableció propiamente una amnistía, pero cuyos efectos son los mismos, excluyendo de los beneficios previstos en ella los crímenes de especial gravedad ${ }^{32}$. Esta amnistía fue diseñada con la ayuda de expertos de la ONU, y además de la exclusión de algunos delitos señaló que para su aplicación se requiere una determinación individualizada de los beneficiarios de la misma ${ }^{33}$.

31. Entrevistas a informantes claves en FESPAD realizadas en San Salvador el 10 de febrero de 2012.

32. Decreto n. ${ }^{\circ} 145$ de 1996, del Congreso de la República, artículo 8: «La extinción de la responsabilidad penal a que se refiere esta ley no será aplicable a los delitos de genocidio, tortura y desaparición forzada, así como aquellos delitos que sean imprescriptibles o que no admitan la extinción de la responsabilidad penal, de conformidad con el derecho interno y los tratados internacionales ratificados por Guatemala».

33. Sobre el impacto de la Ley de Reconciliación, cabe destacar que un estudio «examinó los primeros sesenta casos de solicitud de amnistía en aplicación de esta ley; treinta y nueve de ellos habían sido resueltos, en diecisiete de ellos los solicitantes son identificados como ex policías, ex militares o ex patrulleros, y ninguno de ellos obtuvo el beneficio de la amnistía. Del conjunto de solicitantes, sólo seis recibieron el beneficio solicitado» (Instituto Interuniversitario de Iberoamérica 2005: 151). 
En 1998 la Comisión de Fortalecimiento de la Justicia (CFJ), creada en el marco de los Acuerdos de Paz, emitió su informe Una nueva justicia para la paz, que, además de contener un diagnóstico sobre el estado de la administración de justicia en Guatemala, incluyó un conjunto de recomendaciones tendientes a promover «una transformación de fondo [...] tanto en el marco jurídico del sistema como en su estructura» (CFJ 1998: 9). El informe contiene un apartado sobre recomendaciones para reformas constitucionales referidas a la administración de justicia, emitidas en 1997 y aprobadas por el Congreso en 1998 (Pásara y Wagner 2000: 35). Entre ellas algunas referidas a las funciones e integración de la CSJ, a la administración del Organismo Judicial, a la carrera judicial, a derechos de los pueblos indígenas y a la limitación de la justicia militar (CFJ 1998: 185-189).

En febrero de 1999 la CEH emitió su informe, donde incluyó un capítulo sobre el papel de la justicia durante el conflicto armado interno ${ }^{34}$. Además de contener un panorama del sistema de justicia guatemalteco durante casi tres décadas ${ }^{35}$, el informe recomendó que se investigara, juzgara y condenara a los responsables de delitos no susceptibles de amnistía y de trascendencia internacional, lo que incrementó las demandas de organizaciones de víctimas por justicia, y llevó a que en junio el gobierno tratara de ampliar los efectos de la ley de amnistía de 1996, iniciativa que encontró el rechazo de la Alianza Nueva Nación (Sieder 2002: 270). Sin embargo, el Acuerdo de Oslo había impuesto limitaciones al respecto, al prohibir explícitamente «individualizar responsabilidades» en el informe que surgiera de la Comisión. La CEH sugirió además la reforma judicial como una prioridad de la transición, puesto que una de las conclusiones a las que arribó fue la ineficacia del sistema y la implantación de la impunidad como medio y como fin de la violencia.

También en 1999 entró en vigencia la Ley de la Carrera Judicial, que estableció, entre otras cosas, formas de selección e ingreso de los jueces. Sin embargo, se mantuvo el plazo de nombramiento de cinco años establecido constitucionalmente, claramente restrictivo de la carrera y la independencia judicial, que sin embargo no pudo ser reformado dado el rechazo del referéndum de 1999, tendiente a implementar reformas constitucionales.

34. Algunos aportes del informe de la CEH sobre justicia señalan: «2634. El fracaso de la administración de justicia guatemalteca en la protección de los derechos humanos durante el enfrentamiento armado interno ha quedado clara y plenamente establecido [...] En general, el Poder Judicial se abstuvo de atender los recursos procesales básicos, para controlar al poder público frente a los atropellos graves a la libertad y la seguridad de las personas [...] Además en numerosas ocasiones los tribunales de justicia actuaron directamente subordinados al Poder Ejecutivo, aplicando normas o disposiciones legales contrarias al debido proceso u omitiendo aplicar las que correspondían. 2635. Todo ello colocó a la población en una situación de absoluta indefensión [...]. 2638. Desde 1954 el anticomunismo influyó notablemente en la integración del Organismo Judicial, aumentando su dependencia del ejecutivo, en perjuicio de la tutela de los derechos humanos [...] 2639. [...] la política contrainsurgente influyó también en que la generalidad de los jueces asumiera un concepto de su propia función subordinado a las actuaciones del Gobierno, a fin de posibilitar la represión rápida y eficaz de los opositores políticos» (Denegación de Justicia, CEH, en L. PÁsARA y K. WAGNER 2000: 106-109).

35. «[E]l rigor de la información base y la precisión del examen efectuado hacen de él lectura imprescindible para el investigador de la justicia en Guatemala» (L. PÁSARA y K. WAGNER 2000: 28). 
Además, hasta el 2002 la CSJ no respetaba correctamente los criterios sobre nombramientos establecidos en la ley (Pásara 2010: 289-290).

Según compilación realizada por la Fundación Myrna Mack, la unidad de la Fiscalía de Derechos Humanos, encargada de los casos de violaciones de derechos humanos cometidas durante el conflicto armado, tiene judicializados aproximadamente 1.749 casos. Sin embargo, la exploración en campo sobre el estado de la justicia en este país a la fecha sólo arroja información sobre 33 casos, aun cuando hay otras investigaciones de las que no fue posible recolectar información suficiente para individualizar las causas en las bases de datos.

La investigadora local en el país efectuó solicitudes formales al Ministerio Público y al Organismo Judicial, a través de la unidad de información pública, que se encuentran pendientes de respuesta. También intentó la revisión de expedientes en despachos judiciales, sin resultados positivos en los juzgados. En el Ministerio Público obtuvo alguna información, restringida por la reserva de la investigación. Finalmente intentó obtener información de ONG, con pobres resultados.

De las investigaciones y causas sobre las cuales fue posible recopilar información, tenemos que sus inicios van de 1984 hasta 2012, es decir, desde incluso antes de la expedición del nuevo orden constitucional, en 1984, y mucho antes de los Acuerdos de Paz, hasta la actualidad, como se observa en la Tabla VI. Sin embargo, los avances de estos pocos procesos son notables, si se comparan con El Salvador, donde la mayor parte se encuentran aún en diligencias previas de investigación.

\section{TABLA VI}

RANGO DE FECHAS EN LAS CUALES SE INICIARON LAS INVESTIGACIONES DE LOS CASOS EN GUATEMALA

\begin{tabular}{c|c|c|c}
\hline AÑO & CASOS & AÑO & CASOS \\
\hline 1984 & 2 & 2006 & 3 \\
1990 & 1 & 2007 & 1 \\
1993 & 1 & 2008 & 1 \\
1994 & 2 & 2009 & 1 \\
1995 & 1 & 2010 & 1 \\
1996 & 1 & 2011 & 2 \\
1997 & 3 & 2012 & 4 \\
1998 & 1 & Sin dato & 8 \\
\hline
\end{tabular}

Fuente: Elaboración propia, con base en la información suministrada por la investigadora contratada en el país para el trabajo de campo.

En Guatemala ya hay varios casos con sentencia en firme y con condenas en primera instancia, 13 de los 33 casos que tenemos registrados cuentan con fallo condenatorio, como se ve en la Tabla VII. La reserva de la investigación penal en estos casos se ha levantado, lo que explica que tengamos mayor información sobre ellos, y no sobre los que aún están en trámite en la Fiscalía. Sin embargo, frente al número de violaciones 


\section{E. MARTÍNEZ BARAHONA, M. L. GUTIÉRREZ SALAZAR Y L. RINCÓN FONSECA}

IMPUNIDAD EN EL SALVADOR Y GUATEMALA: «DE LA LOCURA A LA ESPERANZA: ¿¿NUNCA MÁS?»

cometidas en Guatemala siguen siendo muy pocos casos, y todavía resulta sumamente difícil tener acceso a providencias judiciales que en teoría son públicas.

\section{TABLA VII \\ ESTADO DE LOS PROCESOS EN GUATEMALA}

\begin{tabular}{l|c}
\multicolumn{1}{c|}{ ETAPA PROCESAL } & NÚMERO DE PROCESOS \\
\hline Averiguación & 1 \\
Investigación & 17 \\
Primera instancia & 2 \\
Sentencia de primera instancia & 7 \\
Sentencia en firme & 6 \\
\hline
\end{tabular}

Fuente: Elaboración propia, con base en la información suministrada por la investigadora contratada en el país para el trabajo de campo.

Respecto al tipo de violaciones registradas en la base de datos es posible señalar que 16 casos corresponden a desapariciones forzadas, ocho a masacres, tres a genocidio, dos a ejecuciones extrajudiciales, un abuso de autoridad y tres asesinatos. Estos tres casos son dos por la muerte de Myrna Mack, donde primero se juzgó a los autores materiales y posteriormente a los intelectuales, y el otro por la muerte de monseñor Gerardi (ver Tabla VIII). Son pues, a primera vista, casos que podrían ser señalados como paradigmáticos, al igual que las masacres y las desapariciones.

TABLA VIII

RELACIÓN ENTRE EL TIPO DE VIOLACIÓN INVESTIGADO

Y EL ESTADO DE LA INVESTIGACIÓN EN GUATEMALA

\begin{tabular}{l|c|c}
\hline \multirow{2}{*}{$\begin{array}{c}\text { NÚMERO DE INVESTIGACIONES ADELANTADAS } \\
\text { POR TIPO DE VIOLACIÓN }\end{array}$} & \multicolumn{2}{|c}{ ESTADO DE LA ACTIVIDAD JUDICIAL } \\
\cline { 2 - 3 } & $\begin{array}{c}\text { ACTIVO (NO TERMINADA, } \\
\text { EN MOVIMIENTO) }\end{array}$ & $\begin{array}{c}\text { ARCHIVADA } \\
\text { (TERMINADA) }\end{array}$ \\
\hline 16 casos de desaparición forzada & 14 casos & 2 casos (con condena) \\
8 casos de masacres & 7 casos & caso (con condena) \\
3 casos de asesinato & 3 casos (con condena) \\
3 casos de genocidio & 2 casos & $\mathrm{X}$ \\
2 casos de ejecuciones extrajudiciales & 1 caso & $\mathrm{X}$ \\
1 caso de abuso de autoridad & $\mathrm{X}$ \\
\hline
\end{tabular}

Fuente: Elaboración propia, con base en la información suministrada por la investigadora contratada en el país para el trabajo de campo.

En Guatemala es necesario llamar la atención sobre el hecho de que la Corte de Constitucionalidad, en sentencia del 7 de julio de $2009^{36}$, declaró que resulta acorde con

36. Expediente 929-2008. Apelación de incidente de inconstitucionalidad en caso concreto. 
la Constitución aplicar una norma que consagra la desaparición forzada y su carácter de delito «permanente en tanto no se libere a la víctima» (art. 201 del Código Penal), aun cuando la conducta investigada se hubiere iniciado con anterioridad a su expedición, cerrando el paso a las declaratorias de prescripción para este delito.

Gran parte de los casos sobre los cuales se obtuvo información están acompañados por ONG o directamente por familiares de las víctimas, como se ve en la Tabla IX, y la constitución de ellos como partes dentro del proceso, las pruebas que han aportado y los recursos de los que han hecho uso resultan fundamentales a la hora de obtener sentencias condenatorias. A lo anterior se suma el papel positivo que ha jugado el propio Ministerio Público impulsando causas, solicitando reaperturas de procesos sobreseídos e impulsando las actuaciones judiciales.

TABLA IX

RELACIÓN DE CASOS POR ORGANIZACIÓN QUE ACOMPAÑA EL PROCESO

\begin{tabular}{l|c}
\hline \multicolumn{1}{c|}{ ORGANIZACIÓN QUE ACOMPAÑA EL PROCESO } & NÚMERO DE CASOS \\
\hline Famdegua & 5 casos \\
Bufete Jurídico & 5 casos \\
CALDH & 3 casos \\
Familiares de las víctimas, directamente & 4 casos \\
Myrna Mack & 2 casos \\
AVANCSO & 2 casos \\
GAM & 2 casos \\
Abogados sin fronteras & 2 casos \\
Fundación Rigoberta Menchú & 1 caso \\
ADIVIMA & 2 casos \\
ODGAG & 1 caso \\
CAFCA & 1 caso \\
ASF & 1 caso \\
Casos sin información sobre acompañamiento de organizaciones o víctimas & 15 casos \\
\hline
\end{tabular}

Fuente: Elaboración propia, con base en la información suministrada por la investigadora contratada en el país para el trabajo de campo.

Finalmente, los casos registrados implican a 42 autores, en muchos casos militares, miembros de la Policía Nacional o integrantes de las patrullas de autodefensa campesina (PAC), y han conllevado la exhumación de más de 500 víctimas. Por otra parte, sólo se tiene noticia de condena con efectos civiles en el caso de la masacre de Río Negro.

Un ejemplo de las dificultades para llegar a una sentencia condenatoria en Guatemala es el caso adelantado por el asesinato de la antropóloga Myrna Mack, crimen ocurrido el 12 de septiembre de 1990, en el que se vio involucrado de forma directa el aparato represor del Estado. En febrero de 1994 la Corte Suprema emitió sentencia en contra del autor material del hecho y 10 años después, en 2004, se profirió sentencia contra los autores intelectuales. En medio de ambos fallos el proceso se vio plagado de irregularidades, inconvenientes y dilaciones, de los que da cuenta la Corte 
Interamericana de Derechos Humanos, que declaró responsable al Estado guatemalteco por estos hechos ${ }^{37}$.

Los otros casos donde se han proferido fallos son el de monseñor Gerardi, el de la desaparición forzada de ocho habitantes de la aldea de El Jute y el de Choatalum por la desaparición forzada de seis indígenas. También en el caso de Xamán el 9 julio de 2004 se emitió condena por un Tribunal de Sentencia y en 2005 la Corte Suprema de Justicia declaró sin lugar las casaciones presentadas por la defensa. En mayo de 2011 se confirmó la condena por la desaparición de Fernando García y en abril de 2012 se confirmó la condena por la masacre de Dos Erres. Además de estos, hay sentencia de primera instancia por la masacre de 177 personas en la aldea de Río Negro y en marzo de 2012 se profirió sentencia por la masacre perpetrada en la aldea de Plan de Sánchez.

Estas sentencias no pueden hacernos olvidar que en Guatemala las reformas iniciadas aún antes de los Acuerdos de Paz y las impulsadas luego de ellos no han conllevado un impulso suficiente de las causas penales por violaciones a los derechos humanos ocurridas durante el conflicto armado. Después de haber pasado un tiempo considerable, son muy pocos los casos que han llegado hasta la etapa de sentencia. El papel de las víctimas y la sociedad civil ha sido vital para impulsar casos concretos, así como en las reformas propiamente dichas, pero el contraste entre el número de violaciones a los derechos humanos (500.000), los casos investigados por la Fiscalía (aproximadamente 1.700) y las sentencias de las que da cuenta el trabajo de campo (10) es abismal. El genocidio Maya sigue impune y los altos mandos del Ejército y la política involucrados en los crímenes siguen mostrando una gran capacidad de bloqueo a la justicia.

\section{III.3. Reparación}

En El Salvador, a pesar de que en un inicio se estableció un plan de indemnizaciones a favor de los familiares de los muertos en combate y la Comisión de la Verdad recomendó que las víctimas fueran resarcidas y se construyera un monumento con los nombres de los perecidos en la guerra civil, las víctimas de las violaciones a los derechos humanos y sus familias apenas recibieron reparaciones ${ }^{38}$. Los reconocimientos simbólicos en memoria de las víctimas durante los sucesivos gobiernos de ARENA, y el

37. Dichos inconvenientes no se reducen a aspectos procesales, sino que incluyen amenazas de muerte contra los impulsores del proceso y la muerte efectiva del policía que elaboró el informe investigativo del caso.

38. En este sentido, denunciaba R. SIEDER (2002: 262) «Ni Cristiani, ni su sucesor Calderón Sol, ni los miembros del alto mando han reconocido nunca en público la responsabilidad del Estado en las graves violaciones de derechos humanos. Tampoco el FMLN admitió su responsabilidad e hizo caso omiso de quienes aconsejaban que los comandantes guerrilleros señalados en el informe no tuvieran cargos públicos. El gobierno tampoco ha propuesto ningún programa en beneficio de los individuos o comunidades más afectados. No se ha erigido ningún monumento nacional y pocas exhumaciones se han llevado a cabo en las múltiples fosas comunes que hay por todo el país. La exhumación llevada a cabo en El Mozote y el monumento allí levantado -todo bajo los auspicios de la ONU- para conmemorar el asesinato de más de 1.000 personas, constituyen una rara excepción». 
levantamiento en 2003 del Monumento a la Memoria y a la Verdad, fueron siempre promovidos por organizaciones no gubernamentales (Lazo Fuentes y Rey Tristán 2011: 229).

$\mathrm{Al}$ inicio de su gobierno Mauricio Funes recibió de distintas organizaciones asociadas en el Comité Pro Memoria Histórica una propuesta titulada: «Política de garantía de los derechos de las víctimas de violaciones de los derechos humanos» (2010), dando paso a una transformación de la relación entre el gobierno y las víctimas de la guerra, abriendo un espacio de reconocimiento, diálogo y espacios propositivos. Sin embargo, la materialización de políticas de reparación integral y de memoria histórica está todavía pendiente.

Funes ha adelantado una serie de acciones, sobre todo en el plano simbólico: «Condecoración póstuma en 2009 a los padres jesuitas asesinados por el ejército; petición pública de perdón por parte del Presidente en 2010 por las violaciones de derechos humanos de parte de agentes del gobierno durante la guerra; petición de perdón público por el gobierno a la familia de Monseñor Romero en 2010, así como la promoción del gobierno salvadoreño ante la ONU del "Día Internacional del Derecho a la Verdad", el día 24 de marzo de 2011, fecha del asesinato de Monseñor Romero» (Lazo Fuentes y Rey Tristán 2011: 230). El 16 de enero de 2012, en el acto de conmemoración de la masacre de El Mozote, pidió perdón a las víctimas y anunció la creación del programa nacional para víctimas de graves violaciones a los derechos humanos en el marco del conflicto armado en el país.

Mediante el Decreto n..$^{\circ} 5$ del 15 de enero de 2010, y en respuesta a la sentencia de la Corte Interamericana de Derechos Humanos por el caso de las Hermanitas Serrano Cruz, se creó la Comisión Nacional para la Búsqueda de Niños y Niñas desaparecidos, que inició funciones el 14 de marzo de 2011, sin que se cuente a la fecha con algún documento público sobre el avance de su trabajo.

En 2010 se creó la Comisión Nacional de Reparación a las Víctimas de Violaciones a los Derechos Humanos ocurridas durante el conflicto armado interno, mediante el Decreto n. ${ }^{\circ} 57$ del 5 de mayo, sin embargo «el Comité de Derechos Humanos de la ONU ha criticado en su Examen del informe presentado por el Estado la poca profundidad del contenido del Programa Nacional de Reparaciones, pues no asegura de manera amplia todos los aspectos del derecho a la reparación adecuada y no contempla la participación activa de las víctimas» (Lazo Fuentes y Rey Tristán 2011: 230). Así mismo, representantes de varias ONG señalan en las entrevistas que en la actualidad no existe una política de reparación ${ }^{39}$. Al respecto Pro-Búsqueda señala que «[...] no existe una política de memoria histórica que tenga como fin fundamental trabajar el pasado, educarnos en ese sentido, educar a la sociedad, pero sobre todo una política de memoria histórica orientada a decir la verdad, porque toca estructuras [...]. Por eso tenemos una sociedad enferma, porque negamos el pasado, negamos las masacres de 1932, negamos lo que pasó en 1945 y queremos negar lo que ha pasado en el pasado reciente». Indican también como, junto con la propuesta de Política General de Reparaciones (Promemoria), presentó al Estado un proyecto de decreto de reparaciones en el que se

39. Pro-Búsqueda, FESPAD, Tutela Legal, Comité de Expresos Políticos. 
establecían plazos de cumplimiento de éstas, con base en la complejidad de cada una de ellas. Sin embargo, hasta la fecha «lo único que tenemos es lo que dijo el Presidente de la República en El Mozote, que iba a crear una Secretaría General de Reparaciones, eso fue el 16 de enero pero hasta hoy no ha se han dado avances al respecto» ${ }^{40}$.

TABLA X

Políticas DE LA MEMORIA EN El SALVADOR

\begin{tabular}{l|l|l|l}
\hline \multicolumn{1}{c|}{ GOBIERNO } & \multicolumn{1}{c|}{ FECHA } & \multicolumn{1}{|c}{ POLÍtICA Y/O MEDIDA } & \multicolumn{1}{c}{ INICIATIVA } \\
\hline $\begin{array}{l}\text { 20 años de gobiernos } \\
\text { de ARENA }\end{array}$ & $1989-2009$ & $\begin{array}{l}\text { Negación de responsabilidad del Estado y las FF. AA. } \\
\text { en las violaciones a los derechos humanos. }\end{array}$ & Gubernamental \\
\hline Francisco Flórez (ARENA) & 2003 & Monumento a la Memoria y a la Verdad. & ONG \\
\hline $\begin{array}{l}\text { Elías Antonio Saca } \\
\text { González (ARENA) }\end{array}$ & 2007 & $\begin{array}{l}\text { Día de las niñas y niños desaparecidos durante el } \\
\text { conflicto armado. }\end{array}$ & $\begin{array}{l}\text { Gubernamental en } \\
\text { cumplimiento de } \\
\text { Sentencia Corte IDH }\end{array}$ \\
\hline Mauricio Funes (FMLN) & 2009 & Condecoración póstuma a los padres jesuitas. & Gubernamental \\
\cline { 2 - 5 } & 2010 & $\begin{array}{l}\text { Petición pública de perdón por las violaciones a de } \\
\text { derechos humanos de parte de agentes del Estado. }\end{array}$ & Gubernamental \\
\cline { 3 - 5 } & $\begin{array}{l}\text { Petición pública de perdón público a la familia de } \\
\text { monseñor Romero. }\end{array}$ & Gubernamental \\
\cline { 3 - 5 } & $\begin{array}{l}\text { Creación Comisión Nacional para la Búsqueda de } \\
\text { Niños y Niñas desaparecidos. }\end{array}$ & $\begin{array}{l}\text { Gubernamental en } \\
\text { cumplimiento de } \\
\text { Sentencia Corte IDH }\end{array}$ \\
\cline { 3 - 5 } & $\begin{array}{l}\text { Creación Comisión Nacional de Reparación a las } \\
\text { Víctimas de Violaciones a los Derechos Humanos, } \\
\text { con el fin de que proponga el establecimiento de un } \\
\text { programa presidencial de reparación a las víctimas } \\
\text { de graves violaciones a los derechos humanos. }\end{array}$ & Gubernamental \\
\cline { 2 - 5 } & \multirow{2}{*}{2011} & $\begin{array}{l}\text { Promoción del gobierno salvadoreño ante la ONU } \\
\text { del «Día Internacional del Derecho a la Verdad». }\end{array}$ & Sentencia Corte IDH \\
\cline { 2 - 5 } & \multirow{2}{*}{2012} & $\begin{array}{l}\text { Petición pública de perdón a las víctimas de El } \\
\text { Mozote. }\end{array}$ & Gubernamental \\
\hline
\end{tabular}

Fuente: Elaboración propia.

En Guatemala algunas de las recomendaciones de la CEH se encaminaban hacia la implantación de un Programa Nacional de Reparaciones, a la construcción de monumentos conmemorativos y al reconocimiento oficial de responsabilidades ${ }^{41}$. Ya desde los Acuerdos de Paz se hablaba de la obligación del Estado de compensar a las víctimas, e incluso antes se habían hecho exhumaciones de fosas comunes y se habían levantado monumentos. Estas iniciativas, sin embargo, estaban acompañadas del reclamo de justicia para los criminales (Sieder 2002: 269).

40. Entrevistas a informantes claves en Pro-Búsqueda realizadas en San Salvador el 10 de febrero de 2012.

41. En 1999 el gobierno estadounidense expresó su arrepentimiento por su participación en las violaciones a los derechos humanos, y en igual sentido se pronunció la UNRG. 
Con el Acuerdo Gubernativo n. ${ }^{\circ} 258$ de 7 de mayo de 2003 se creó el Programa Nacional de Resarcimiento (PNR), reformado con los Acuerdos Gubernativos n. ${ }^{\circ}$ 1882004 y 619-2005, con una vigencia mínima de trece años, para el «resarcimiento individual y/o colectivo de las víctimas civiles de violaciones a los derechos humanos y de delitos de lesa humanidad, cometidos durante el conflicto armado interno» (art. 1). El Acuerdo previó la posibilidad de remitirse a normas internacionales para definir e interpretar los delitos que cubre, así como a los informes de la Comisión de Esclarecimiento Histórico (CEH) y del Sistema de Naciones Unidas. Dicho Acuerdo creó además la Comisión Nacional de Resarcimiento (CNR) como responsable de la coordinación, supervisión y seguimiento del programa, integrada por cinco miembros, todos dependientes directamente del Presidente de la República.

Las medidas previstas para implementar el resarcimiento son: la dignificación de las víctimas, el resarcimiento cultural, la reparación psicosocial y la rehabilitación, la restitución material y el resarcimiento económico, mientras su financiación se deja en manos de una asignación anual incluida en el presupuesto general de ingresos y gastos del Estado, la cooperación local e internacional y «donaciones, herencias y legados» (art. 8), sin embargo en la página del programa ${ }^{42}$ sólo se incluye información orientativa sobre el mismo, pero no sobre sus resultados. Según informaciones de prensa, el presupuesto que se asigna al PNR es insuficiente y se destina gran parte a gastos de funcionamiento, mientras con lo que queda el acento se pone en actos de dignificación a las víctimas, construcción de casas e impulso de proyectos productivos ${ }^{43}$.

El 25 de febrero -día en el que la CEH presentó su informe final- se estableció como fecha oficial para cada año conmemorar el Día Nacional de la Dignidad de las Víctimas del Conflicto Armado, mediante Decreto n. ${ }^{\circ}$ 06-2004, reformado por el Decreto n. ${ }^{\circ} 48$ 2008. En este último se estableció además que «El Ministerio de Educación deberá incluir en la currícula de educación primaria y secundaria las enseñanzas sobre las causas y consecuencias del enfrentamiento armado y del contenido de los Acuerdos de Paz» (art. 1).

Las Memorias de Labores de 2008 y 2009 del Programa Nacional de Resarcimiento ${ }^{44}$ dan cuenta de 8.518 resarcimientos monetarios en 2008, acompañados de una petición escrita de perdón por parte del gobierno a cada uno de los beneficiarios, ello frente a los reclamos de resarcimiento de 64.705 personas. Así mismo se da cuenta de la presentación de 1.552 denuncias al Ministerio Público y de indemnizaciones a 9.827 personas, en una cuantía total de 193.358.595,00 Quetzales, que, según se anuncia, representa un incremento del 14\% en relación con el año anterior. En 2009 la Memoria de Labores habla del traslado de 7.377 expedientes al Ministerio Público con testimonios de víctimas del conflicto, a fin de que se inicie la correspondiente investigación, así como de la restitución de 888 viviendas y el resarcimiento monetario a 4.088 beneficiarios, por un monto de 90.112.308,97 Quetzales. En ambos años los informes hablan de medidas tendientes al resarcimiento cultural y a la dignificación de víctimas.

42. http://www.pnr.gob.gt (acceso, 22 de abril de 2012).

43. ReYNOLDS, Luisa. El Estado asigna pocos fondos para resarcimiento. El Periódico, 30 de marzo, 2011.

44. http://www.pnr.gob.gt/inicio/biblioteca/pnr/index.html (acceso, 8 de mayo de 2012). 
E. MARTÍNEZ BARAHONA, M. L. GUTIÉRREZ SALAZAR Y L. RINCÓN FONSECA IMPUNIDAD EN EL SALVADOR Y GUATEMALA:

«DE LA LOCURA A LA ESPERANZA: ¿NUNCA MÁS?»

TABLA XI

Políticas DE LA MEMORIA EN GUATEMALA

\begin{tabular}{|c|c|c|c|}
\hline GOBIERNO & FECHA & POLÍTICA Y/O MEDIDA & INICIATIVA \\
\hline \multirow[t]{3}{*}{ Alfonso Portillo (FRG) } & 2000 & Proyectos piloto de resarcimiento. & SEPAZ \\
\hline & 2002 & $\begin{array}{l}\text { Ley que declara el Día Nacional de la Dignidad de las } \\
\text { Víctimas de la Violencia. }\end{array}$ & ONG \\
\hline & $2003-2016$ & $\begin{array}{l}\text { Programa Nacional de Resarcimiento (PNR): prevé una } \\
\text { serie de medidas (simbólicas, económicas y psicoso- } \\
\text { ciales) de las que no se hacen públicos todos los datos } \\
\text { sobre sus resultados y aplicación. }\end{array}$ & Gubernamental \\
\hline \multirow[t]{3}{*}{ Óscar Berger (GANA) } & \multirow[t]{2}{*}{2004} & Creación de la Comisión Nacional de Resarcimiento. & Gubernamental \\
\hline & & $\begin{array}{l}\text { Establecimiento del Día Nacional de la Dignidad de } \\
\text { las Víctimas del Conflicto Armado. }\end{array}$ & Legislativa \\
\hline & 2005 & $\begin{array}{l}\text { Modificaciones al Programa Nacional de } \\
\text { Resarcimiento. }\end{array}$ & Gubernamental \\
\hline \multirow[t]{4}{*}{ Álvaro Colom (UNE) } & 2008 & $\begin{array}{l}\text { Establecimiento de enseñanzas sobre el enfrenta- } \\
\text { miento armado y los Acuerdos de Paz. }\end{array}$ & Legislativa \\
\hline & 2008 & $\begin{array}{l}\text { Labores en el marco del PNR: } \\
\text { Resarcimientos monetarios por 193.358.595,00 Q. } \\
\text { Presentación de } 1.552 \text { denuncias. }\end{array}$ & Gubernamental \\
\hline & 2009 & $\begin{array}{l}\text { Labores en el marco del PNR: } \\
\text { Resarcimientos monetarios por 90.112.308,97 Q. } \\
\text { Presentación de } 7.377 \text { denuncias. }\end{array}$ & Gubernamental \\
\hline & 2009 & $\begin{array}{l}\text { Creación de la Comisión de Desclasificación de los } \\
\text { Archivos Militares. }\end{array}$ & Gubernamental \\
\hline
\end{tabular}

Fuente: Elaboración propia.

La Corte IDH ha ordenado reparaciones monetarias en todos los casos que ha conocido, incluyendo -en algunos- reparaciones simbólicas y/o colectivas. Las condenas de la Corte al Estado guatemalteco superan por mucho las reparaciones del PNR, generando disparidades y descontento entre víctimas que se encuentran en situaciones similares, a lo que se suman otros problemas prácticos, como identificación de víctimas de masacres y amenazas o robos a los beneficiarios de las reparaciones (Mersky y Roth-Arriaza 2007). Por otro lado, dicha Corte entiende la justicia misma como una forma de reparación, así lo dejó sentado al considerar que «emitir una sentencia en donde se entre al fondo del asunto constituye una forma de reparación para la víctima y sus familiares y a su vez, constituye una manera de evitar que se vuelvan a repetir [los] hechos» (Corte IDH, 2003: 27).

\section{BUSCANDO RESPUESTAS A LA IMPUNIDAD}

Como se ha visto antes, de acuerdo a la literatura sobre justicia transicional y postransicional, las explicaciones sobre la presencia o ausencia de juicios por responsabilidad civil y penal, por graves violaciones a los derechos humanos cometidas por los regímenes militatres del pasado, se deben a varios factores que podríamos agrupar en 
factores institucionales, jurídicos y sociales. En este sentido, dentro de los factores institucionales podríamos mencionar la configuración institucional de las relaciones Ejecutivo/Judicial, la independencia judicial y las interferencias de los militares en las decisiones políticas y judiciales. La existencia de leyes de amnistía así como su interpretación judicial y la ratificación de instrumentos internacionales, así como interpretaciones de cortes internacionales por las nacionales, serían los factores jurídicos principales. Entre los factores sociales, podemos indicar la actividad de Organizaciones de Derechos Humanos (ODH) en favor de los juicios, su constancia, incremento o renuncia. Por último, los factores externos estarían configurados por el apoyo de redes internacionales; el clima internacional; así como las presiones de Cortes extranjeras donde se estén llevando a cabo procesos judiciales sobre de violaciones de derechos humanos cometidos en los países en cuestión.

En cuanto a los factores institucionales, en Guatemala podría hablarse de un marco propicio para los juicios, aun cuando se mantienen limitantes como la inestabilidad de los nombramientos judiciales y las intereferencias de intereses políticos en los nombramientos. En El Salvador, por el contrario, la reforma judicial implementada después de los Acuerdos de Paz no ha servido para cambiar los resultados de accountability (Sieder 2002: 276), y el cambio y receptividad judicial ha sido prácticamente imperceptible (Collins 2010: 168).

Un aspecto diametralmente opuesto en los dos países, y que se ha hecho evidente con el trabajo de campo, es el manejo que se ha dado desde el ente acusador a estas investigaciones. Mientras en Guatemala hay una unidad de la Fiscalía encargada de los casos de violaciones de derechos humanos cometidas durante el conflicto armado, y se han creado Fiscalías Especializadas para el conocimiento de masacres, como la de Xamán, por ejemplo, a lo que se suma que las fuentes consultadas son unánimes en señalar que la institución se encuentra en cabeza de una persona que ha mostrado interés en que estos procesos avancen, en El Salvador ha habido un bloqueo de estos procesos desde sus inicios.

Skaar (2011: 41-43) advierte que la amenaza militar en Guatemala continúa siendo muy alta, en contraste con El Salvador, lo que, atendiendo a la independencia judicial «formal» que se predica de ambos países luego de las reformas, debería dar lugar más fácilmente a juicios en el segundo país. Sin embargo, llama la atención sobre la falta de implementación de muchas de las reformas salvadoreñas y, en consecuencia, sobre la diferencia entre independencia de jure e independencia de facto, así como sobre la debilidad de las demandas de justicia en este país. Como se vio antes, Collins (2010) también llama la atención sobre este último aspecto. Por su parte, Collins (2010: 173-174) apunta como posibles causas de la impunidad en El Salvador la amnistía, la falta de pruebas, la falta de voluntad de los jueces de primera instancia para revertir la tradición de impunidad, la falta de demandas particulares de justicia y el bloqueo que la Fiscalía ejerce.

En cuanto a las leyes de amnistía, la diferencia entre los dos países sigue siendo grande, pues mientras en Guatemala hay una ley que en todo caso prevé exclusiones para su aplicación, dejando por fuera determinado tipos de delitos de trascendencia para la comunidad internacional, la ley en El Salvador es amplísima y no ha habido pronunciamientos 
judiciales encaminados a modularla de forma efectiva, a lo que se suma que en este país se mantiene el debate paz/justicia, así como el pulso político de los dos grupos políticos protagonistas de los acuerdos de paz, elementos propios de los estudios clásicos de justicia transicional que idealmente deberían haberse superado con el paso del tiempo.

En esta misma línea, cabe anotar que sin que pueda hablarse de grandes avances en Guatemala, sí que es cierto que en este país los jueces se han mostrado más receptivos a incorporar jurisprudencia y conceptos del derecho internacional al ámbito interno, tratándose de violaciones a los derechos humanos, manteniendo limitaciones al fuero militar o ratificando el carácter permanente del delito de desaparición forzada. Ello sin embargo no puede hacer que olvidemos otras decisiones, adoptadas también por altas Cortes del país, donde han prevalecido otros intereses, como es el caso de aquella del 12 de diciembre de 2007, donde se negaron las extradiciones solicitadas por la justicia española ${ }^{45}$, como las más recientes, en las que en trámites de amparo la Corte de Constitucionalidad ha bloqueado la reapertura del proceso seguido por la desaparición y muerte de Efraín Bámaca Velázquez, desconociendo lo ordenado por la Corte Interamericana de Derechos Humanos.

Tanto en Guatemala como en El Salvador la investigación de campo permitió detectar problemas de comunicación y colaboración entre las ONG que acompañan los casos, así como problemas de manejo y circulación de información al interior de las propias organizaciones. A pesar de ello la situación parece ser más crítica en El Salvador, donde se constata lo observado en otros estudios en cuanto a la debilidad de estas organizaciones y la falta de tradición de demandas legales y estrategias de litigio. Sólo dos de las organizaciones consultadas en este país demuestran una estrategia dirigida a casos tipo -Pro-Búsqueda hacia casos de desaparición forzada de niños y niñas y Madeleine Lagadec hacia casos de masacres-, lo cual, si bien no ha favorecido el impulso de las causas, ha servido para poner en la agenda de debate este tipo de violaciones y lograr avances de políticas públicas.

\section{CONCLusión}

La sistematización del estado de los procesos judiciales relacionados con casos de violaciones a los derechos humanos durante los conflictos armados en Guatemala y El Salvador es un avance relevante respecto a la visibilización y análisis de la impunidad en ambos países, debido a que hasta la fecha no se cuenta con estudios que ofrezcan información detallada respecto al estado judicial de estos casos. Sin embargo, los inconvenientes de acceso a la información que se hacen patentes a lo largo del artículo implican restricciones en la profundidad de los datos obtenidos.

45. Por delitos ocurridos en Guatemala entre 1978 y 1986, entre los que se encontraban el genocidio ocurrido durante el conflicto, el asalto a la Embajada de España, en el que fallecieron incineradas 37 personas, así como la muerte de sacerdotes españoles, delitos de los que serían presuntos responsables autoridades civiles y militares del país, entre ellas Efraín Ríos Montt. 
En cualquier caso, nos encontramos ante dos países con conflictos largos y sangrientos, donde el Estado es responsable de la mayor parte de las violaciones a los derechos humanos y donde el poder militar aún ha mantenido su poder sobre las autoridades civiles. A pesar de ello y contrario a lo esperado por algunos autores, el enjuiciamiento de las violaciones de derechos humanos no ha puesto en riesgo la democracia (Booth Walling y Sikkink 2008) sino todo lo contrario, al igual que tampoco el paso del tiempo ha disminuido la judicialización de dichas violaciones (argumento esgrimido por Huntington 1991). Estos argumentos se han visto revaluados en el Cono Sur y más tímidamente en Centroamérica, donde las demandas por justicia se mantienen.

Las medidas adoptadas en un principio, en ambos países, giraron en torno a la VERDAD. Mientras que en Guatemala se tradujo en una amplia documentación del horror vivido (un esfuerzo que, sin embargo, dejó como víctimas a monseñor Gerardi y Myrna Mack), en El Salvador, en cambio, se trató de una verdad incompleta, centrada en casos paradigmáticos, y que por lo tanto mantiene invisibilizadas a gran cantidad de víctimas.

En cuanto a la JUSTICIA, aun cuando los Acuerdos de Paz en ambos países insistieran en la necesidad de implementar de reformas judiciales y poner fin a la impunidad, ésta se ha mantenido. A ello han contribuido las leyes de amnistía aprobadas, con diferentes efectos: mientras la de El Salvador es la más amplia de este tipo en la región, la de Guatemala prevé razonables exclusiones, lo que, sin embargo, no ha impedido que se utilice como medida de dilación de los procesos, al reclamarse su aplicación reiteradamente por los encausados.

Las leyes de amnistía no son, sin embargo, las únicas responsables de la injusticia reinante en estos países. En El Salvador, las restricciones impuestas a las víctimas para impulsar los procesos, aunadas a la total ausencia de voluntad de justicia por parte de los operadores judiciales desde los inicios mismos de las investigaciones, así como la falta de independencia de quienes encabezan la Fiscalía y los propios jueces, agravado por la falta de coordinación y estrategia judicial de las ONG que acompañan o impulsan los procesos y la ausencia de una política gubernamental al respecto, hacen que la impunidad sea total y absoluta. Prueba de ello es que no se ha producido un solo fallo por parte de la justicia nacional frente a las miles de graves violaciones a los derechos humanos ocurridas durante el conflicto.

En Guatemala, las pocas sentencias de las que se da cuenta son un indicio de avances en materia de justicia. Es importante destacar en este país el esfuerzo hecho desde la Fiscalía para impulsar estos casos y crear unidades especializadas de investigación. Sin embargo, quienes promueven los procesos lo hacen poniendo en ello grandes esfuerzos e incluso arriesgando su propia seguridad, lo que necesariamente deja fuera de los reclamos de justicia a un gran número de víctimas, muchas de ellas indígenas y con enormes dificultades para enfrentarse a poderes fácticos. Dichos poderes se presentan capaces de frenar esfuerzos de justicia incluso a los niveles más altos de la judicatura, donde la inestabilidad en el nombramiento de jueces y los períodos tan cortos de dichos nombramientos inciden negativamente en la independencia de los juzgadores.

Finalmente, en cuanto a las medidas de REPARACION, cabe llamar la atención sobre la escasez de esfuerzos realizados respecto no sólo a medidas y políticas adoptadas, sino 
también en cuanto a la absoluta opacidad del desarrollo de los mismos. En este sentido, resulta imposible descubrir, por ejemplo, cuáles son los resultados arrojados por el ambicioso Programa Nacional de Resarcimiento (que ya lleva casi una década funcionando en Guatemala), como tampoco es posible conocer el informe de la Comisión Nacional, que sería la guía para la implementación de un programa de reparación en dicho país.

Las múltiples dificultades con que se encuentra la justicia postransicional en Guatemala y El Salvador pueden hacer pensar en el abandono del reclamo de los derechos de verdad, justicia y reparación, o pueden, por el contrario, hacer pensar en la necesidad de hacer mayores esfuerzos para consolidar la democratización de estos países, aumentar la independencia de sus jueces e investigadores y conseguir la dignificación de todas aquellas personas que sobrevivieron a la crueldad estatal. Lo que sí es evidente es que sus propias decisiones políticas (muchas de ellas cristalizadas en deficiencias en el cumplimiento de lo postulado en las comisiones de la verdad) han hecho casi imposible tanto la justicia retributiva (aquella concebida para rectificar profundas injusticias a través de la restauración de la dignidad humana y civil de las víctimas) como la restaurativa (aquella que se caracteriza por ocuparse de reconstruir relaciones sociales y políticas fracturadas, que busca la reconciliación social).

En cuanto a verdad y reparación, pasados los avances también han sido escasos. En El Salvador hasta hace muy poco el Estado ni siquiera reconocía responsabilidad por sus crímenes y aún hoy se rinden honores a militares violadores de derechos humanos, mientras en Guatemala ha sido elegido Presidente de la Republica un militar cuestionado por estos temas. En ambos países las pocas medidas adoptadas lo han sido desde el Ejecutivo, sin que logren institucionalizarse y mantenerse con los cambios de gobierno. Las medidas simbólicas han provenido de iniciativas no gubernamentales. Así, más allá de los resultados iniciales arrojados por las Comisiones de la Verdad -en todo caso parciales en El Salvador-, las miles de víctimas de los conflictos que vivieron en estos países, la gran mayoría víctimas del propio Estado, no tienen esperanza de que se hagan efectivos sus derechos de verdad, justicia y reparación, ni garantía de que la locura no se repetirá nunca más.

\section{BIBLIOGRAFÍA}

Aguilar, Paloma; Balcells, Laia y Cebolla, Héctor. Determinants of Attitudes towards Transitional Justice: An Empirical Analysis of the Spanish Case. Comparative Political Studies, 2011, vol. 44 (10): 1397-1430.

AlCÁntara, Manuel. Sistemas Políticos de América Latina. Volumen II. México, América Central y El Caribe. Madrid: Tecnos, 2008.

Barahona de Brito, Alexandra; Aguilar Fernández, Paloma y GonZales Enríquez, Carmen (eds.). Las politicas hacia el pasado. Juicios, depuraciones, perdón y olvido en las nuevas democracias. Madrid: Ediciones Istmo, 2002.

Booth WaLling, Carrie y SikKINK, Kathryn. La cascada de justicia y el impacto de los juicios de derechos humanos en América Latina. Cuadernos del CLAEH, 2008, vol. 96-97: 15-40. 
Collins, Cath. Post-transitional Justice. Human Rights Trials in Chile and El Salvador. Pennsylvania: Editorial Penn State Press, 2010.

COMISIÓN DE FORTALECIMIENTO DE LA Justicia. Una nueva justicia para la paz. Guatemala: Magna Terra Editores, 1998.

Comisión PARA el EsClarecimiento HistóRICo (CEH). Guatemala Memoria del Silencio. Guatemala: Oficina de Servicios para Proyectos de las Naciones Unidas, 1999.

Corte InTERAmericana de Derechos Humanos. Sentencia del 25 de noviembre de 2003. Caso Myrna Mack vs. Guatemala.

CORTÉS RODAS, Francisco. Los derechos de las víctimas de la violencia política a la verdad, la reparación y la justicia. Reflexiones sobre cuatro casos en América Latina. Estudios Políticos, 2007, vol. 31: 61-86.

COURTIS, Cristian. Breves apuntes de caracterización de la actividad política de los tribunales. En Ojesto, Fernando; Orozco Henríquez, Jesús y VÁzquez, Rodolfo (coords.). Jueces y Politica. México, D.F.: Editorial Porrúa, 2005: 59-84.

Domingo, Pilar. Judicialization of Politic or Politicization of the Judiciary? Recent Trends in Latin America. Democratization, 2004, vol. 11 (1): 104-126.

Domingo, Pilar. Reformas judiciales y Justicia Transicional en América Latina: sus interacciones. Paper presentado en el seminario de investigación del Área de Ciencia Política de la Universidad de Salamanca, 17 marzo, 2011.

Du ToIT, André. The moral foundations of the South Africa TRC: Truth as Acknowledgment and justice as recognition. En Rotberg, Robert I. y ThOMPson Dennis (eds.). Truth v. justice: The morality of truth commissions. Princeton: Princeton University Press, 1999.

ELSTER, Jon. On doing what one can: An argument against post-communist restitution and retribution. En KRITZ, Niel J. (ed.). Transitional Justice: How Emerging Democracies Reckon with Former Regimes. Washington D.C.: United States Institute of Peace Press, 1995.

Epstein, Lee; KNIGHT, Jack y MARTin, Andrew D. The Supreme Court as a Strategic National Policymaker. Emory Law Journal, 2001, vol. 50: 583-611.

EpsteIn, Lee; KNIGHT, Jack y SHveTSOva, Olga. The Role of Constitutional Courts in the Establishment and Maintenance of Democratic Systems of Government. Paper presented at the annual meeting of the American Political Science Association. Washington D.C., 2000.

GutiéRrez SalazAR, Martha Liliana. Poder Judicial y Justicia Transicional: El rol de los jueces en la protección de derechos bumanos en Guatemala. Salamanca. Tesis de Máster en estudios Latinoamericanos del Instituto de Iberoamérica, Universidad de Salamanca, 2011.

Gutmann, Amy y ThOmpson, Dennis. The moral foundations of truth commissions. En RoTBERG, Robert I. y THOMPSOn, Dennis (eds.). Truth $v$. justice: The morality of truth commissions. Princeton: Princeton University Press, 2000.

HeLmKe, Gretchen y SANDERS, Mitchell S. Modeling Motivations: A Method for Inferring Judicial Goals from Behavior. The Journal of Politics, 2006, vol. 68 (4): 867-878.

Huntington, Samuel P. How Long. En The Third Wave. Democratization in the Late Twentieth Century. London: University of Oklahoma Press, 1991.

Instituto Interuniversitario De IberoaméricA. Perfil de Gobernabilidad de Guatemala. Red Eurolatinoamericana de Gobernabilidad para el Desarrollo (REDGOB). Salamanca: Ediciones Universidad de Salamanca, 2005.

KAPISZEWSKI, Diana. Tactical balancing and Prioritizing Pragmatism: High Court Decision-making on Economic Policy Cases in Brazil. Paper prepared for delivery at the conference Judicial Politics in Latin America. México D.F.: CIDE, March 4-8, 2009.

KAPISZEWSKI, Diana; TAYLOR, Matthew. Doing Courts Justice? Studying Judicial Politics in Latin America. Perspectives on Politics, 2008, vol. 6: 741-767. 
KARL, Terry Lynn. Dilemmas of Democratization in Latin America. Comparative Politics, 1990, vol. 23 (1): 1-21.

KeCK, Margaret E. y SikKInK, Kathryn. Activist beyond Borders: Advocacy Networks in International Politics. Ithaca y London: Cornell University Press, 1998.

Kiss, Elizabeth. Moral ambition within and beyond political constraints: Reflections on Restorative Justice. En ROtBerg, Robert I. y ThOMPSON, Dennis (eds.). Truth v. justice: The morality of truth commissions. Princeton: Princeton University Press, 2000.

KnIGHT, Jack y EpSTEIn, Lee. On the struggle for Judicial Supremacy. Law and Society Review, 1996a, vol. 30 (1): 87-120.

Knight, Jack y EpSteIn, Lee. The Norm of Stare Decisis. American Journal of Political Science, 1996b, vol. 40 (4): 1019-1935.

Lazo Fuentes, Xiomara y Rey Tristán, Eduardo. ¿Es la justicia el precio de la paz? Logros y limitaciones en el proceso de paz salvadoreño. En REY TRISTÁn, Eduardo y CAGIAO VILA, Pilar (coords.). Conflicto, memoria y pasados traumáticos: El Salvador contemporáneo. Santiago de Compostela: Universidad de Santiago de Compostela, 2011: 211-240.

LeONARDo SEgura, Mónica. Guatemala. Las víctimas y la justicia transicional ¿Están cumpliendo los Estados latinoamericanos con los estándares internacionales? Washington D.C.: Fundación para el Debido Proceso Legal, 2010.

Malamud-Goti, Jaime. Game Without End. State Terrorism and the Politics of Justice. Norman: University of Oklahoma Press, 1996.

Malamud-Goti, Jaime. Los dilemas morales de la Justicia Internacional. Buenos Aires: Ciepp-Miño y Dávila Editores, 2003.

Martínez Barahona, Elena. Seeking the Political Role of the third government branch. A comparative approach to High Courts in Central America. Liepzig: vDM Verlag Dr. Müller, 2009.

McADAms, James (ed.). Transitional Justice and the Rule of Law in New Democracies. Notre Dame: University of Notre Dame Press, 1997.

Mersky, Marcie y Roth-ARRIAZA, Naomi. Guatemala. Due Process of Law Foundation and United States Institute of Pace. Victims Unsilenced. The Inter-American Human Rights System and Transitional Justice in Latin America. Washington D.C., 2007.

NALEPA, M. Skeletons in the closet: Transitional justice in post-communist Europe. New York: Cambridge University Press, 2010a.

NALEPA, M. Captured Commitments: An Analytic Narrative of Transitions with Transitional Justice. World Politics, 2010b, vol. 62 (2): 341-380.

O’Donnell, Guillermo y SCHMITTER, Phillipe. Transiciones desde un gobierno autoritario. Conclusiones tentativas sobre las democracias inciertas, vol. 4. Buenos Aires: Paidós, 1986.

Osiel, Mark. Respuestas estatales a las atrocidades masivas. En RETTBERG, Angelika (ed.). Entre el Perdón y el Paredón. Bogotá: Universidad de los Andes, 2005: 67-80.

PÁsARA, Luis. Paz, ilusión y cambio en Guatemala. El proceso de paz, sus actores, logros y límites. Ciudad de Guatemala: Instituto de Investigaciones Jurídicas, Universidad Rafael Landívar, 2003.

PÁSARA, Luis. Las normas de derechos humanos de origen internacional y el orden interno. Zacatecas: Tribunal Superior de Justicia del Estado de Zacatecas, 2005.

PÁsARA, Luis. Reforma de la justicia en Centroamérica: ¿el vaso medio vacío o medio lleno? En Los sistemas judiciales en Centroamérica. Madrid: Fundación Carolina-CeALCI, 2006.

PÁsARA, Luis. Ley, justicia y sociedad en América Latina. México, D.F.: Instituto de Investigaciones Jurídicas, Universidad Nacional Autónoma de México, 2010.

PÁsara, Luis y Wagner, Karin. La justicia en Guatemala. Bibliografía y documentos básicos. Ciudad de Guatemala: MINUGUA, 2000. 
Peruzzotti, Enrique y Smulovitz, Catalina. Accountability Social, la otra cara del control. En Peruzzotti, Enrique y Smulovitz, Catalina (eds.). Controlando la política. Ciudadanos y Medios en las Nuevas Democracias Latinoamericanas. Buenos Aires: Editorial Temas, 2002.

PeruzzotTi, Enrique y SMUlovitz, Catalina. Enforcing the rule of law: social accountability in the new Latin American democracies. Pittsburgh: University of Pittsburgh Press, 2006.

POPKIN, Margaret. Peace without justice: Obstacles to building the rule of law in El Salvador. University Park: The Pennsylvania State University, 2000.

Risse, Thomas y SikKInK, Kathryn. The socialization of international human rights norms in to domestic practices: introduction. En RISSE, Thomas; RoOP, Stephen y SIKKINK, Kathryn (eds.). The power of Human Rights. International Norms and Domestic Change. Cambridge: Cambridge University Press, 1999.

RoOP, Stephen y SIKKINK, Kathryn. International norms and domestic politics in Chile and Guatemala. En Risse, Thomas; ROOP, Stephen y SIKKINK, Kathryn (eds.). The power of Human Rights. International Norms and Domestic Change. Cambridge: Cambridge University Press, 1999.

Roth-ARRIAZA, Naomi. El papel de los actores internacionales en los procesos nacionales de responsabilidad. En BARAHONA DE BRITO, Alexandra et al. (eds.). Las políticas hacia el pasado. Juicios, depuraciones, perdón y olvido en las nuevas democracias. Madrid: Ediciones Istmo, 2002: 71-101.

Roth-ArRiaZA, Naomi. The new landscape of transitional justice. En Roth-ArRIAZA, Naomi y MARIEZCURRENA, Javier (eds.). Transitional Justice in the Twenty-First Century. Cambridge: Cambridge University Press, 2006.

Sieder, Rachel. Políticas de Guerra, Paz y Memoria en América Central. En BARAHONA DE BRITO, Alexandra et al. (eds.). Las políticas hacia el pasado. Juicios, depuraciones, perdón y olvido en las nuevas democracias. Madrid: Ediciones Istmo, 2002: 247-284.

SIEDER, Rachel. Renegociando la ley y el orden. Reforma Judicial y respuesta de la ciudadanía en la Guatemala de la postguerra. América Latina Hoy, 2003, vol. 35: 61-86.

SIEDER, Rachel; SCHJOLDEN, Line y ANgELL, Alan (eds.). The Judicialization of Politics in Latin America. New York: Palgrave Macmillan, 2005.

SKAAR, Elin. Judicial Independence and Human Rights in Latin America: Violations, Politics, and Prosecution. New York: Palgrave Macmillan, 2011.

SOMMER, Ehud N. y SEKERCIOGLU, M. Eser. Institutional antecedents of strategic judicial decisionmaking. Paper presented at the Midwest Political Science Association Annual Meeting. Chicago, April 2007.

Tate, C. Neal y ValLinder, Torbjörn (eds.). The Global Expansion of Judicial Power. New York: New York University Press, 1995.

Teitel, Ruti. G. Transitional Justice Genealogy. Harvard Human Rights Journal, 2003, vol. 16: 69-94.

VALENCIA Villa, Hernando. Introducción a la justicia transicional. Conferencia magistral impartida en la cátedra Latinoamericana «Julio Cortázar» de la Universidad de Guadalajara, México, 26 de octubre de 2007. Publicada en Claves de Razón Práctica, n. ${ }^{\circ}$ 180. Madrid, 2007: 76-82.

\section{ENTREVISTAS REALIZADAS}

Informantes claves en Pro-Búsqueda, FESPAD, Tutela Legal, Comité de Expresos Políticos (El Salvador, febrero 2012).

Informantes claves en Myrna Mack y CALDH (Guatemala, febrero 2012). 